\title{
ASNA-1 oxidation induced by cisplatin exposure enhances its cytotoxicity by selectively perturbing tail anchored protein targeting.
}

Running title: ASNA-1 and cisplatin sensitivity

Dorota Raj ${ }^{1,} \dagger$, Ola Billing ${ }^{2,} \dagger$, Agnieszka Podraza ${ }^{1,} \dagger$, Oskar Hemmingsson, ${ }^{2}$, Gautam $\mathrm{Kao}^{1, *}$ and Peter Naredi, ${ }^{1,3, *}$

${ }^{1}$ Department of Surgery, Institute of Clinical Sciences, Sahlgrenska Academy, University of Gothenburg, SE413 45 Gothenburg, Sweden

${ }^{2}$ Department of Surgical and Perioperative Sciences, Surgery, Umeå University, SE901 85 Umeå, Sweden

${ }^{3}$ Department of Surgery, Sahlgrenska University Hospital, SE413 45 Gothenburg, Sweden $\dagger$ These authors contributed equally

*Corresponding author: peter.naredi@gu.se; gautam.kao@gu.se

Keywords: ASNA-1; Caenorhabditis elegans; cisplatin; drug sensitivity; redox; tail-anchored protein

\section{SUMMARY STATEMENT}

Sensitizing tumors to cisplatin would be of considerable therapeutic benefit. Here we show a novel mechanism of cisplatin sensitization via oxidation of ASNA-1 in a Caenorhabditis elegans model.

\begin{abstract}
Cisplatin is a frontline cancer treatment, but intrinsic or acquired resistance is common. We previously showed that ASNA-1/TRC40 inactivation increases cisplatin sensitivity in mammalian cells and a Caenorhabditis elegans asna-1 knockdown model. ASNA-1 has conserved tail-anchored protein (TAP) targeting and insulin secretion functions. Here we examined the mechanism of ASNA-1 action. We show that ASNA-1 exists in two physiologically-responsive redox states with separable TAP-targeting and insulin secretion functions. Cisplatin-generated ROS targeted ASNA-1 oxidation, resulting in a selective targeting defect of an ASNA-1-dependent TAP. Increased ASNA-1 oxidation sensitized worms to cisplatin cytotoxicity. Mutants with a redox balance favoring oxidized ASNA-1 were cisplatin sensitive as null mutants by diverting ASNA-1 away from its TAP-targeting role and
\end{abstract}


instead perturbing endoplasmic reticulum (ER) function. Mutations in the ASNA-1 receptor required for TAP insertion induced equivalent cisplatin sensitivity. We reveal a previously undescribed cellular dysfunction induced by cisplatin, identify a cisplatin target, and show that drug exposure causes TAP targeting-induced ER dysfunction. Therapeutic oxidation of ASNA1 could be a clinically useful means to increase cisplatin sensitivity, reduce cytotoxic drug doses, and counteract cisplatin resistance.

\section{AUTHOR SUMMARY}

Cisplatin is a very effective anti-cancer drug and is widely used as a frontline treatment. However, tumor resistance limits its use. Tumor re-sensitization would improve cancer treatment. ASNA-1/TRC40 knockdown in Caenorhabditis elegans and mammals results in cisplatin hypersensitivity, but the underlying mechanistic details are largely unknown. We show that in $C$. elegans ASNA-1 mutants, increased cisplatin killing is coupled with delocalization of a tail-anchored protein, SEC-61 $\beta$, a membrane protein that should reach the ER and is instead mistargeted. Like its homologs, the reduced form of worm ASNA-1 is needed for targeting activity. Targeting is blocked upon ASNA-1 oxidation after cisplatin treatment, likely via reactive oxygen species (ROS) generated by cisplatin treatment. Nevertheless, the oxidized form of the protein can execute other functions like insulin secretion. We show also that mutants with high oxidized ASNA-1 levels are cisplatin sensitive. Additionally, cisplatin induced mistargeting strictly acts through ASNA-1 inactivation. Thus, we define a pathway from cisplatin exposure that targets protein (ASNA-1) inactivation, consequently leading to mis-targeting of proteins that need ASNA-1 for their maturation. This multi-step process provides vital information about likely proteins that can be targeted by drugs to enhance cisplatin mediated killing and improve chemotherapy.

\section{INTRODUCTION}

Solid tumors consist of both dividing and non-dividing post-mitotic cells (Komlodi-Pasztor et al., 2012), and both populations must be eliminated to reduce tumor bulk. The frontline cytotoxic chemotherapy cisplatin rapidly kills both dividing and non-dividing cells but via different mechanisms (Stewart, 2007). In dividing cells, cisplatin directly binds to DNA to cause DNA damage, cell cycle arrest, and apoptosis (Kelland, 2007; Legin et al., 2014). In nondividing cells, it kills by binding to antioxidants like glutathione, elevating reactive oxygen 
species (ROS) levels that have downstream effects on a variety of cellular processes (Dasari and Tchounwou, 2014). Identification of proteins that are rapidly oxidized after cisplatin exposure would provide important information on the mechanism of cisplatin-induced death in post-mitotic cells. If cytotoxicity requires the oxidation of specific proteins, their targeted oxidation could be combined with lower doses of cisplatin to achieve equivalent anti-tumor activity as high-dose single agent regimens. The longstanding limitation of cisplatin use is the eventual development of tumor resistance and significant side-effects of nephrotoxicity and ototoxicity. The use of lower but effective doses would address these important limitations.

ASNA-1/TRC40/GET3 is a redox-sensitive protein whose knockdown increases the sensitivity of tumor cells to cisplatin-induced death (Hemmingsson et al., 2009). We previously established Caenorhabditis elegans as a relevant system to model the cisplatin killing effect in mammalian post-mitotic cells, since $C$. elegans asna-1 mutants are sensitive to cisplatininduced death (Hemmingsson et al., 2010). Human ASNA-1/TRC40 can act as a functional substitute in worm mutants, further underlining the model's similarity to human cells (Kao et al., 2007). We have also shown that ASNA-1 in mouse and C. elegans promotes insulin secretion and that targeted mouse knockouts develop type 2 diabetes (T2D) (Kao et al., 2007; Norlin et al., 2016). This work led us to propose that the cisplatin response and insulin secretion functions are separable (Hemmingsson et al., 2010).

A possible molecular basis for the separation of functions emerges from extensive cellular and structural biology studies on ASNA-1 homologs in yeast, mammals, and plants (Mateja et al., 2009; Mateja et al., 2015; Srivastava et al., 2016; Voth et al., 2014). The yeast homolog GET3 can adopt two alternative redox-sensitive forms with non-overlapping functions (Voth et al., 2014). The best understood function is of the reduced dimeric form, which acts as part of a targeting complex to guide tail-anchored membrane proteins (TAPs) for insertion into the endoplasmic reticulum (ER) membrane (Favaloro et al., 2008; Schuldiner et al., 2008; Stefanovic and Hegde, 2007). However, GET3 can also act as a general chaperone and a holdase by adopting an oxidized tetrameric structure with internal disulfide bonds via oxidation of critical redox-sensitive cysteines (Powis et al., 2013; Voth et al., 2014). In vitro, GET3 adopts a zinc-stabilized conformation needed for TAP targeting when conserved cysteines are reduced but acts as a holdase and general chaperone when these residues are oxidized (Voth et al., 2014). Thus, a better understanding of how ASNA-1 works and which form of the protein should be targeted in different pathologies requires matching the disease with the molecular state before rational drug regimens can be devised. 
Here we investigated links between cisplatin-induced oxidative stress, the redox-responsive nature of ASNA-1, and the role of ASNA-1 in cisplatin cytotoxicity. ASNA-1 is needed for ER targeting of a model TAP via its ER-localized receptor WRB-1. Specifically, we asked whether ASNA-1 activity in worms can be targeted and modified by cisplatin exposure and whether this would explain its role as a sensitivity factor. We show that reduced monomeric ASNA-1 (ASNA-1 ${ }^{\text {RED }}$ ) protects the organism from cisplatin cytotoxicity. Cisplatin generates ROS, and drug exposure rapidly leads to higher levels of oxidized ASNA-1 (ASNA-1 ${ }^{\text {OX }}$ ) at the expense of ASNA-1 ${ }^{\text {RED }}$ and cisplatin treatment in wild-type worms perturbs model TAP targeting in an ASNA-1 dependent manner. Cisplatin-induced oxidation of ASNA-1 is not a bystander effect. Rather, mutants with increased levels of oxidized ASNA-1 are sensitive to cisplatin death. We find that increased oxidation of ASNA-1 is equivalent to complete depletion of ASNA-1 with respect to cisplatin response without having any effect on its insulin secretion function. Increased levels of oxidized ASNA-1 also re-distributes the protein away from its juxtamembrane localization. Failure of TAP targeting is important for cisplatin-induced death, because $w r b-1^{-/}$mutants are also cisplatin sensitive. Thus, we delineate a pathway in which cisplatin-induced ROS generation inactivates the cisplatin response function of ASNA-1, which in turn perturbs the targeting of a TAP protein to the ER membrane. Taken together, our studies identify ASNA-1 as a biologically relevant cisplatin target, reveal which molecular form of ASNA-1 is modulated, and demonstrates that one strategy to increase cisplatin sensitivity would be biasing ASNA-1 to the oxidized state.

\section{RESULTS}

\section{ASNA-1 is present in physiologically redox-sensitive states}

The oxidation state of the $S$. cerevisiae ASNA-1 homolog, GET3, modulates its activities. We therefore asked whether $C$. elegans ASNA-1 could also act as a redox-regulated switch and whether this switch responds to internal physiological changes. We performed non-reducing SDS-PAGE on proteins isolated from wild-type worms (Fig. 1A) and control worms expressing ASNA-1::GFP (Fig. 1B-H), and found that C. elegans ASNA-1 was present in both its oxidized and reduced states (Fig. 1A-H). GFP alone was not detected in the oxidized state (Fig. 1H). Consistent with the findings in yeast (Voth et al., 2014), there was no oxidation of ASNA$1::$ GFP when two conserved cysteines at positions 285 and 288 were substituted for serines (Fig. 1G). Moreover, the balance between ASNA-1:GFPOX and ASNA-1:GFPRED could be 
altered by exposure of worms to different pro-oxidants: $10 \mathrm{mM} \mathrm{H}_{2} \mathrm{O}_{2} / 1 \mathrm{mM} \mathrm{CuSO}_{4}$ (Fig. 1B) or $5 \mathrm{mM}$ sodium arsenite (Fig. 1C). ASNA-1:GFP ${ }^{\mathrm{OX}}$ was diminished by exposing animals to the antioxidant mitoTempo (Fig. 1D). The balance shifted towards more ASNA-1:GFPOX at the expense of ASNA-1:GFPRED in sod-2(gk257) and mev-1(knl) mutants, which have high endogenous ROS levels (Fig. 1E,F) (Labuschagne et al., 2013). We concluded that ASNA-1 exists in two alternative molecular states and that their balance can be altered by environmental factors and internal physiological changes.

\section{ASNA-1 promotion of TAP insertion is independent of its role in insulin secretion}

We next examined whether redox-induced structural changes in ASNA-1 impacted its wellstudied functions and whether these functions were affected by alterations of the cellular ASNA-1 redox balance. While the ASNA-1/TRC40 pathway guides TAPs to the ER membrane, other pathways (EMC, HSP70/HSC40, SND) can potentially compensate for the absence of ASNA-1 to produce little overall defect in TAP targeting (Aviram and Schuldiner, 2017). To investigate whether the TAP targeting function was affected by the absence of worm ASNA-1, we established an in vivo model for TAP targeting in C. elegans. In vertebrates and yeast, SEC61 $\beta$ is a model TAP that requires ASNA1/TRC40 for correct targeting to the ER membrane (Favaloro et al., 2008; Hegde and Keenan, 2011; Schuldiner et al., 2008; Stefanovic and Hegde, 2007) via binding of ASNA-1 homologs to the transmembrane domain (TMD) of SEC61 $\beta$. This domain is highly conserved in the C. elegans homolog sec-61.B (hereafter called SEC61 $\beta$ ). Indeed, Co-IP/MS/MS analysis detected SEC61 $\beta$ as an ASNA-1::GFP-interacting partner (Table 1). Cell fractionation using GFP-tagged SEC61 $\beta$ confirmed that the protein was found only in the membrane fraction, even when expressed under a strong intestine-specific promoter (Fig. 2F). Co-expression of GFP::SEC-61 $\beta$ in intestinal cells of wild-type $C$. elegans with the mCherry-tagged rough ER (RER)-specific protein, SP12 (spcs-1), resulted in near complete colocalization in a pattern characteristic of ER (Fig. 2A,B and Fig. S1). This colocalization pattern was disrupted in animals expressing GFP::SEC61 $\beta^{\triangle \mathrm{TMD}}$ with its TMD deleted. Instead, large aggregates of GFP::SEC61 $\beta^{\triangle \mathrm{TMD}}$ accumulated in cytoplasmic regions distinct from the RER (Fig. 2A,B). Taken together, this established that worm SEC-61 $\beta$ was an ASNA-1-interacting partner that localized to the ER membranes via its TMD and thus was a good model protein to further study the contribution of ASNA-1 to TAP targeting. This localization required ASNA-1 since, in the two worm asna-1 protein null mutants (ok938 and sv42) (Kao et al., 2007), the ER localization of GFP::SEC-61 $\beta$ was significantly decreased and the protein was instead detected in cytoplasmic foci (Fig. 2A,B). The targeting defect was solely 
due to lack of ASNA-1, since wild-type ASNA-1 expressed from a transgene completely rescued the TAP targeting defect (Fig. 2A,B and Fig. S1). Detection of the same phenotype in two independent deletion mutants and rescue with wild-type ASNA-1 ruled out any contribution from background genetic effects.

TEM analysis of asna-1 (ok938) mutants revealed aggregates containing misfolded proteins and dilated RER lumina (Fig. S2A,S2B). The ER membrane was also found in autophagosomes (Fig. S2C), an ER stress-related structure, very similar to that seen in ASNA-1-deficient mice (Norlin et al., 2016). As expected, a transgene-based assay also revealed that autophagy levels were high in asna-1(ok938) mutants (Fig. S2D). The abnormal RER membranes in mutant animals were competent for proper membrane targeting of another TAP, the worm homologue of CytB5 (cytb-5.1), an ASNA-1-independent, ER-specific TAP (Abell et al., 2007; Stefanovic and Hegde, 2007), which localized to the ER in asna-1(ok938) mutants to the same extent as in wild-type animals (Fig. 2A, 6B). This was also true for another ASNA-1- independent TAP, SERP-1.1(F59F4.2) (Fig. 6A,B). These findings further underscored the validity of our in vivo model, since it enabled us to distinguish between ASNA-1-dependent and independent TAP insertion.

asna-1 mutants have multiple phenotypes including elevated autophagy levels (Fig. S2D), high ER stress (Natarajan et al., 2013), and low insulin signaling levels (Hemmingsson et al., 2010; Kao et al., 2007). We asked whether these phenotypes contribute to the TAP targeting defect in asna-1(ok938) mutants. Inducing ER stress in wild-type animals to levels equivalent to asna1(ok938) mutants (Fig. S2E) and did not affect GFP::SEC-61 $\beta$ targeting (Fig. 2C). Starvation, which reduces insulin signaling and increases autophagy levels in C. elegans (Henderson and Johnson, 2001) and disrupts insulin secretion in unc-31/CAPS (Speese et al., 2007) mutants, did not affect GFP::SEC-61 $\beta$ targeting to the ER (Fig. 2C). Conversely, forcing high levels of DAF-28/insulin secretion in the tom-1/tomosyn mutant (Gracheva et al., 2007) failed to suppress the TAP targeting defect of asna-1(ok938) animals (Fig. 2C). Therefore, changes in ER morphology, insulin secretion activity, autophagy, or ER stress levels do not contribute to TAP targeting defects in asna-1 mutants. These findings support the hypothesis that the insulin secretion function of ASNA-1 and high ER stress levels do not contribute to defective TAP targeting in asna-1 mutants, thereby providing the first evidence of independent ASNA-1 functions in C. elegans.

\section{A receptor for TAP insertion interacts with ASNA-1 and has a role in cisplatin detoxification}


ASNA-1-mediated insertion of TAPs requires a receptor at the ER membrane. WRB is a component of the heterodimeric receptor for TAP targeting (Vilardi et al., 2011). Its C. elegans homolog WRB-1 is the likely receptor for ASNA-1. Using co-IP/MS/MS analysis, we detected WRB-1 as an interaction partner of ASNA-1::GFP (Table 1). Western blot analysis showed a significant decrease in ASNA-1 protein levels in wrb-1(tm5938) mutants (Fig. 2D) indicative of their intracellular association. WRB-1::GFP was detected in the ER (Fig. 2E) and was required for GFP::SEC-61 $\beta$ targeting to the ER membrane (Fig. 2A,B) to roughly the same extent as ASNA-1. Furthermore, wrb-1(tm5938) produced a phenotype similar to asna-1 mutants for proteinaceous aggregates (Fig. S2A), swollen ER (Fig. S2B), and autophagosomes (Fig. S2C). To determine whether WRB-1 is required for other ASNA-1 functions such as cisplatin responses, we tested the survival of $w r b-1$ (tm5938) mutants after exposure to cisplatin; $w r b-1$ mutants displayed cisplatin hypersensitivity (Fig. 3D). Thus, mutations in two different genes that similarly affect TAP targeting also demonstrated increased cisplatin sensitivity, suggesting that TAP targeting is associated with cisplatin sensitivity.

\section{Cisplatin sensitivity is associated with TAP delocalization but not insulin secretion}

We have previously shown that animals lacking asna- 1 activity reversibly arrest at the L1 stage and have defective insulin/IGF signaling (IIS). Furthermore, adult asna-1(ok938) mutants are pale, small, and sterile due to severe germline defects (Kao et al., 2007). While both ASNA-1 and WRB-1 mutants cause GFP::SEC-61 $\beta$ localization defects (Fig. 2A,B), wrb-1(tm5938) mutant adults are larger and have better developed germlines (Fig. 3A,B), indicating that TAPtargeting defects can be separated from the growth and body size phenotypes associated with insulin signaling defects. To directly determine whether WRB-1 loss leads to insulin secretion defects, we used two transgene reporters reporting IIS activity: DAF-16/FOXO::GFP (Henderson and Johnson, 2001) and DAF-28/insulin::GFP (Kao et al., 2007). In contrast to asna-1(ok938) mutants, wrb-1(tm5938) mutants had no DAF-28::GFP secretion defect (Fig. 3C), even though ASNA-1 protein levels were reduced (Fig. 2D). Furthermore, DAF16/FOXO::GFP was always cytoplasmic in wrb-1(RNAi) animals, indicating high IIS levels (Fig. 3D). By contrast, DAF-16/FOXO:GFP localizes to the nuclei upon asna-1 knockdown due to insulin signaling defects(Kao et al., 2007). asna-1 (Kao et al., 2007) and insulin receptor mutants (Gems et al., 1998) exhibit reversible first larval stage arrest (Fig. S3). This characteristic insulin pathway growth defect was not observed when both maternal and zygotic wrb-1(m-z-) gene activity (Fig. S3A, S3B) were depleted. Taken together, these results show that, compared to mutants of its physical interaction partner ASNA-1, wrb-1 mutants show no 
insulin secretion or signaling defects. Therefore, cisplatin sensitivity and TAP targeting defects are not associated with insulin secretion defects.

\section{Altered redox balance that favors ASNA-1 ${ }^{\text {Ox }}$ causes cisplatin sensitivity}

To obtain direct evidence for the separable functions of ASNA-1, we tested a set of asna-1 point mutant strains for cisplatin sensitivity (Thompson et al., 2013). asna-1 (gk592672) substitutes a highly conserved alanine at position 63 to a valine, hereafter called asna-1(A63V). This mutation did not affect the ASNA-1 protein stability (Fig. 4A). Transgene-expressed ASNA-1 ${ }^{\mathrm{A} 63 \mathrm{~V}}::$ GFP protein was detected in the ER (Fig. 4B). The 13-times outcrossed asna$1(\mathrm{~A} 63 \mathrm{~V})$ mutant was as sensitive to cisplatin exposure as the deletion mutant, and this phenotype was rescued by wild type transgene-expressed ASNA-1::GFP (Fig. 4C). This transgene also rescued the ASNA-1 protein null mutant for the cisplatin sensitivity phenotype (Fig. 4C). However, while as cisplatin sensitive as the deletion mutant, asna-1(A63V) animals had neither the insulin signaling/secretion defect (Fig. 4F,G) nor the enhanced ER stress phenotypes of the deletion mutant (Figure S4A-C). The animals were fertile with normal brood sizes (Fig. S4E), had properly developed germlines (Fig. 4D,E), and displayed a wild type lifespan (Fig. S4D). asna-1(A63V) animals had no TAP targeting defects (Fig. 4H,I), but membrane fractionation revealed reduced membrane association of the ASNA-1 ${ }^{\mathrm{A} 63 \mathrm{~V}}:: \mathrm{GFP}$ protein compared to those with ASNA-1 $1^{+}$GFP (Fig. 4J,K). Further analysis revealed a strong defect in GFP::SEC-61 $\beta$ localization to the ER membrane in wild type animals as well as in asna-1 $(A 63 V)$ mutants when challenged with cisplatin (Figure 4H,I).

The antioxidant epigallocatechin gallate (EGCG) reduces cisplatin effectiveness (Pan et al., 2015) and has been used as an antioxidant in several C. elegans studies (Xiong et al., 2018; Zhang et al., 2009). Notably, pre-treatment with EGCG reduced asna-1(A63V) cisplatin sensitivity but had no protective effect in the asna-1 deletion mutant (Fig. 4C). Modulation of cisplatin sensitivity by EGCG suggested that the effect of the A63V change might alter the balance between oxidized and reduced ASNA-1 and that ASNA-1 was a direct target for the antioxidant effect of EGCG. Comparison of oxidized and reduced ASNA-1 ${ }^{\mathrm{A} 63 \mathrm{~V}}:: \mathrm{GFP}$ to ASNA-1::GFP revealed that the point mutation shifted the balance from the reduced to the oxidized form (Fig. 4L,M), indicating that a shift to more oxidized ASNA-1 caused increased cisplatin sensitivity. To examine this further, we tested the redox balance in worms expressing ASNA-1 ${ }^{\triangle \mathrm{His} 164}:$ GFP, which is inactive for rescue of the cisplatin response phenotype (Hemmingsson et al., 2010). Again, substantially more oxidized ASNA-1 was detected (Fig. 4L,M). To examine this further, we tested an asna-1(4His164) mutant strain generated by 
Crispr/CAS9 technology. This strain was as sensitive to cisplatin as the asna-1(ok938) deletion mutant (Fig. 4C). Thus, two ASNA-1 mutants that displayed increased oxidation were as sensitive to cisplatin as the deletion mutants. Moreover, sod-2(gk257) and mev-1(knl) mutants, which harbor high levels of ASNA-1 ${ }^{\text {OX }}$ without changes in overall ASNA-1 levels (Fig. 1C,D), were also cisplatin sensitive (Fig. 6C). Taken together, a redox balance that favors oxidized ASNA-1 results in the same cisplatin sensitivity phenotype as complete depletion of ASNA-1, leading to the conclusion that reduced ASNA-1 protects against cisplatin toxicity. Notably, cisplatin sensitivity becomes a redox-sensitive event in the asna- $1^{A 63 V}$ genetic background, indicating a strategy to modulate its killing effect. Strikingly, the shift in ASNA-1 ${ }^{\text {A63V }}$ to the oxidized state occurred even in the absence of an increase in the expression of markers of ER stress ( $h s p-4)$ (Fig. S4A-C), mitochondrial stress ( $h s p-6$ and $h s p-60)$ (Fig. S4F), or oxidative stress (gst-4, gst-30 and gst-38) (Fig. S4G) in contrast to high ROS levels in sod-2(gk257) and mev-1(knl) mutants. We conclude that the A63V and $\Delta$ His 164 mutants in ASNA-1, which have inherently high ASNA-1 ${ }^{\text {OX }}$ levels, are sensitive to cisplatin but have normal insulin secretion function. This analysis proves that the redox balance of ASNA-1 is necessary for maintaining its essential functions and that reduced ASNA-1 protects against cisplatin toxicity, most likely through its TAP targeting activity.

\section{Cisplatin inactivates the protective function of ASNA-1 by converting it to the oxidized} state

Having shown that reduced ASNA-1 is protective, we sought to examine whether part of cisplatin's killing mechanism was by directly targeting and inactivating ASNA-1. Several groups have shown in mammalian cancer cell models that a central feature of cisplatin treatment is oxidative stress induction and ROS generation (Brozovic et al., 2010; Choi et al., 2015; Itoh et al., 2011; Lu et al., 2016). Since ASNA-1 is required for cisplatin resistance and ASNA-1 function is modulated by oxidation, we next asked if cisplatin exposure induced oxidative stress in C. elegans. A short cisplatin exposure regimen was chosen at $300 \mu \mathrm{g} / \mathrm{mL}$ or $600 \mu \mathrm{g} / \mathrm{mL}$, since these concentrations do not decrease the viability of wild-type animals, thereby allowing meaningful cell biology analysis. These experimental conditions were indeed sufficient to induce significant elevations in ROS (Fig. 5D), increased protein carbonylation (Fig. 5C), and robustly activate the oxidative stress response genes $g c s-1$ and gst-4 (Fig. 5A,B). We next tested whether cisplatin exposure influences the oxidation state of ASNA-1. ASNA-1::GFPexpressing worms were exposed to cisplatin at a concentration that significantly reduced the survival of asna-1(ok938) mutants without affecting wild-type animals (Fig. 4C). Under these 
conditions, the balance of ASNA-1::GFP shifted towards the oxidized form (Fig. 5E,F). Thus, cisplatin exposure directly increases asna-1 oxidation, allowing us to conclude that ASNA-1 is a molecular target of cisplatin.

\section{Cisplatin selectively delocalizes an ASNA-1-dependent TAP from the ER}

Having established that ASNA- $1^{\text {RED }}$ protects against cisplatin toxicity and mindful of the role of the reduced form in TAP targeting, we next determined whether cisplatin treatment and TAP targeting were directly related. To this end, we tested whether the increased oxidized ASNA-1 observed in cisplatin-treated worms resulted in a biologically meaningful outcome. Exposure of asna-1(+) animals expressing GFP::SEC61 $\beta$ to cisplatin significantly delocalized this TAP away from the ER membrane at levels similar to those seen in untreated asna-1(ok938) animals (Fig. 6A,B). Remarkably, cisplatin treatment had no effect on the ER localization of the two ASNA-1-independent TAPs CytB5.1 (cytb-5.1) and SERP-1.1 (Fig. 6A,B). Quantitative confocal microscopy revealed that conditions that substantially delocalized GFP::SEC-61 $\beta$ had no effect on the ER localization of GFP::CYTB-5.1 and GFP::SERP-1.1. Therefore, delocalization of GFP::SEC-61 $\beta$ in cisplatin-treated worms was not due to more a more generalized effect on membrane integrity. We next tested the effect of cisplatin exposure on DAF-28/insulin::GFP secretion and observed no secretion defect (Fig. 5G); the membrane events associated with insulin maturation, packaging into dense core vesicles, and release were unaffected. Therefore, the effects on GFP::SEC-61 $\beta$ localization were not caused by general cisplatin effects on cellular function and animal health. Since cisplatin oxidizes ASNA-1 and shifts the protein to its non-TAP associated role, we next asked whether GFP::SEC-61 $\beta$ delocalization in cisplatin-treated animals was solely via its modulation of ASNA-1 activity or due to another role in this process. ER targeting of GFP::SEC61 $\beta$ was compared in asna1(ok938) mutants with and without cisplatin treatment; GFP::SEC61 $\beta$ was delocalized to the same extent in both conditions (Fig. 6A,B). Since there was no additive effect, cisplatin exposure requires ASNA-1 activity to exert its TAP delocalization effect.

Our studies support the hypothesis that cisplatin directly targets ASNA-1, leading to its rapid oxidation without affecting insulin secretion. We conclude that a shift in redox balance that lowers ASNA-1 ${ }^{\text {RED }}$ levels blocks insertion of its client TAP into the ER membrane. Furthermore, cisplatin treatment of wild-type worms phenocopied the asna-1 deletion mutant phenotype for delocalization of GFP::SEC61 $\beta$ but not for the insulin secretion function. The ER is an organelle whose function is affected by cisplatin exposure via its effect on ASNA-1 oxidation. 


\section{DISCUSSION}

Cisplatin-generated ROS is a central event in post-mitotic cells. The precise targets of these oxygen species are poorly understood, and their identification remains critical to understanding cisplatin cytotoxicity. Here we identified ASNA-1 as an oxidative stress-induced molecular target of cisplatin and provide a molecular basis for the cisplatin hypersensitivity caused by ASNA-1 knockdown.

This study was underpinned by the observations that cisplatin induces oxidative stress (Itoh et al., 2011), ASNA-1 knockdown increases sensitivity to cisplatin (Hemmingsson et al., 2010), that the yeast homolog, GET3, exists in both oxidized and reduced states, and that GET3 must be reduced to target some TAPs to the ER membrane (Voth et al., 2014). Using live cell imaging, we have shown that worm ASNA-1 also has TAP targeting activity and that WRB-1 is its likely receptor for this function. $w r b-1$ mutants were also cisplatin sensitive, thereby linking TAP targeting to cisplatin sensitivity and uncovering a new cisplatin sensitivity factor. ASNA-1 existed in both oxidized and reduced states in a manner requiring redox-reactive cysteines. We provide several lines of evidence showing that elevated ASNA-1 ${ }^{\text {OX }}$ levels increases cisplatin sensitivity. Strikingly, a redox-imbalanced mutant that favored accumulation of ASNA-1 ${ }^{\text {OX }}$ was as sensitive as a mutant lacking ASNA-1. Cisplatin exposure rapidly increased ROS and ASNA-1 ${ }^{\text {OX }}$ levels. Moreover, an ASNA-1-dependent TAP was specifically delocalized as a result of cisplatin treatment.

\section{ASNA-1 is required for a TAP-targeting protein}

We characterized the TAP-targeting activity of C. elegans ASNA-1 and found that it possesses robust TAP targeting activity shared with its binding partner, the ER-localized protein WRB1. C. elegans asna-1 has all the structural features required for TAP insertion (Chio et al., 2019)(Mateja and Keenan, 2018; Mateja et al., 2009). However, since not all ASNA-1 homologs have TAP-targeting activity (Farkas et al., 2019), it was important to examine whether $C$. elegans ASNA-1 has this function. In addition, parallel pathways like EMC, HSP70/HSC40, and SND participate in TAP targeting (Aviram et al., 2016; Casson et al., 2017; Cho and Shan, 2018; Guna et al., 2018). It was possible that compensated TAP targeting by these pathways would make it difficult to detect a targeting defect in asna-1 single mutants. Consequently, it was important to establish the in vivo contribution of ASNA-1 to TAP targeting in intact animals. We assayed this activity in large intestinal cells, because ASNA-1 
expressed by these cells was amenable to quantitative confocal microscopy. We showed that the other pathways do not bypass the need for ASNA-1 activity, since SEC-61ß, which binds to ASNA-1 (Table 1), was significantly delocalized in asna-1 mutants (Fig. 2A,B). Importantly, using this assay, we also found two ASNA-1-independent ER-localized TAPs (Fig. 6A), in agreement with findings in other systems (Colombo et al., 2009; Favaloro et al., 2008; Stefanovic and Hegde, 2007). The contribution of other pathways to the targeting of ASNA-1-dependent TAPs in worms is unclear. It is possible that if TAP targeting is studied in C. elegans tissues other than the intestines, the EMC or the HSP70/HSC40 pathways may play a greater role in the process.

\section{WRB-1 participates in TAP targeting and is the likely ER receptor for ASNA-1}

C. elegans WRB-1 was identified as the closest homolog of mammalian WRB, containing two predicted trans-membrane domains and the important coiled-coil domain. Evidence that WRB1 is the receptor for the ASNA-1/TAP complex comes from the fact that it was ER-localized (Fig. 2E) and was an ASNA-1-binding protein (Table 1), as with its homologs in other species (Carvalho et al., 2019; Vilardi et al., 2011). Moreover, ASNA-1 protein levels were lower in wrb-1 mutants (Fig. 2D), a property also seen upon mammalian WRB knockdown (Colombo et al., 2016; Rivera-Monroy et al., 2016). Taken together, these three properties of WRB-1 satisfy the requirement to regard this protein as the ER-based receptor. Crucially, TAP localization was defective in two wrb-1 mutants to a similar extent seen in asna-1 mutants (Fig. 2B).

\section{Cisplatin cytotoxicity is linked to defects in TAP targeting but not the insulin secretion function of ASNA-1}

The observation that TAP targeting was defective in $w r b-1$ mutants allowed us to address two important questions about TAP protein function. First, we showed that $w r b-1$ mutants were also hypersensitive to cisplatin (Fig. 3D), thus identifying mutants in two separate genes with TAP targeting and cisplatin hypersensitivity function. Second, we found that wrb-1 mutants were not defective in insulin/IIS signaling and secretion function (Fig. 3), as observed in asna-1 mutants (Kao et al., 2007). We therefore concluded that insulin/IIS signaling pathway defects play no role in the asna-1(-) cisplatin hypersensitivity phenotype. Moreover, this also meant that ASNA-1-dependent TAP targeting has little role in ASNA-1-induced DAF-28/insulin secretion. This was consistent with our previous finding that daf-2/insulin receptor mutants without insulin signaling capacity are completely resistant to cisplatin (Hemmingsson et al., 
2010). Further evidence that the cisplatin and insulin functions of ASNA-1 are separable emerged from the analysis of the asna-1 $(A 63 \mathrm{~V})$ mutant, which had the striking phenotype of completely separating the cisplatin and insulin secretion functions (Fig. 4): "null" for the cisplatin phenotype and "wild-type" for the growth and insulin secretion function of ASNA-1.

Since ASNA-1 protein levels were similar in wild-type and the asna-1(A63V) mutant (Fig. 4A), this functional separability (cisplatin versus insulin secretion) was not due to a threshold effect, in which a differential phenotypic effect would be seen if one function required less total ASNA-1 protein.

\section{C. elegans ASNA-1 is a redox-sensitive protein \\ C. elegans ASNA-1 exists in both reduced (ASNA-1 ${ }^{\mathrm{RED}}$ ) and oxidized (ASNA-1 ${ }^{\mathrm{OX}}$ ) forms (Fig.} 1, Fig. 7A). This is consistent with Voth et al. (2014), who showed that yeast GET3 changes from a reduced, ATPase-dependent TAP targeting state to an oxidized ATPase-independent general chaperone/holdase state. The ASNA-1 ${ }^{\text {RED }} / A S N A-1^{\text {OX }}$ balance was biologically relevant, since it was sensitive to changes in animal physiology. Worm mutants with high ROS levels or cultivation conditions that increase ROS shifted the balance towards more oxidized ASNA-1, while exposure to antioxidants shifted the balance in the opposite direction (Fig. 1). The ASNA-1 ${ }^{\text {RED } / A S N A-1 ~}{ }^{\text {OX }}$ balance had biological relevance, since cisplatin sensitivity was increased in the asna-1 $(A 63 \mathrm{~V})$ mutant that produced a preferentially oxidized protein variant (Fig. 4L, Fig. 7B). Notably, the cisplatin hypersensitivity of asna-1(A63V) animals was reduced by pre-treatment with the antioxidant EGCG, indicating that the redox state of ASNA1(A63V) is relevant for cisplatin cytotoxicity (Fig. 4C). Reversal of the cisplatin sensitivity phenotype with antioxidants strongly supports this conclusion. The shift in the ASNA$1^{\text {RED} / A S N A-~}{ }^{\text {OX }}$ balance towards higher ASNA- $1^{\text {OX }}$ levels is not a peculiarity of the alanine 63 mutation; indeed, ASNA-1 ${ }^{\Delta \mathrm{His} 164}$ displayed even higher ASNA-1 ${ }^{\text {OX }}$ levels (Fig. 4L). Transgenic expression of ASNA-1 ${ }^{\Delta \mathrm{His} 164}$ does not rescue cisplatin hypersensitivity of the null mutant but maintains largely intact insulin/IGF signaling (Hemmingsson et al., 2010). We speculate that ASNA-1 point mutants that are TAP-targeting defective exist at higher levels in the oxidized state.

ASNA-1 is member of a group of $C$. elegans proteins, along with PRDX-2, IRE-1, and GLB12, whose activity changes with oxidation (Henau et al., 2015; Hourihan et al., 2016; Oláhová et al., 2008). In vivo redox changes are dynamic in C. elegans with respect to both tissue type and age (Back et al., 2012; David et al., 2010; Walther et al., 2015). Oxidized proteins are likely 
to be widespread in the proteome, since quantitative redox proteomics has identified many proteins with redox-sensitive cysteines in $\mathrm{H}_{2} \mathrm{O}_{2}$-treated animals (Kumsta et al., 2011) and in day 2 adults (Knoefler et al., 2012).

\section{Increased levels of oxidized ASNA-1 sensitize cells to cisplatin killing}

Only $5-10 \%$ of cisplatin is found in the nuclei of exposed cells, the remainder being cytoplasmic and membrane associated (Brozovic et al., 2010). Non-nuclear cisplatin has been shown to modify kinase signaling, $\mathrm{Ca}^{2}+$ pump activity, and membrane dynamics (Brozovic et al., 2010; Dasari and Tchounwou, 2014). In light of our findings that cisplatin modifies ASNA-1 function (Fig. 7B), it will be instructive to study which - if any - of these processes are caused by changes in ASNA-1 oxidation levels and ASNA-1-dependent TAP targeting. Our study shows that cisplatin has an effect on the ER in worm intestinal cells, which was not due to a general effect on cellular membranes at the concentrations of cisplatin used, since only ASNA-1-dependent TAPs were delocalized and ASNA-1-independent TAPs were targeted normally (Fig. 6). Further, this treatment had no effect on DAF-28/insulin secretion, a process that also requires several membrane budding and fusion events at various cellular locations (Fig. 5G). The normal insulin secretion levels detected in cisplatin-treated animals suggest that Golgi and plasma membranes are largely competent.

Most cells in human solid tumors are in a post-mitotic state (Komlodi-Pasztor et al., 2012), similar to in adult worms. Given the range of effects exerted by cisplatin on cellular function, the killing effect cannot only be attributed to induced DNA damage but is also likely to be partially be due to effects on the ER. We have shown that increased levels of oxidized ASNA1 beyond a certain threshold will sensitize cells to cisplatin. We propose that small molecule drugs that increase oxidized ASNA-1 at the expense of the reduced form will enhance cisplatin cytotoxicity. Conversely, the antioxidant EGCG reduces cisplatin effectiveness. This work also reveals for the first time that cisplatin impacts TAP targeting. The cellular biology of the TAP pathway has been studied in detail and the roles of several other proteins besides ASNA1/TRC40 delineated. It is likely that small molecule drugs that affect other components of the TAP targeting pathway would also increase cisplatin sensitivity; indeed, wrb-1 mutants were as sensitive as asna-1 mutants and also represent a new cisplatin sensitivity factor. This analysis of ASNA-1 demonstrates that cisplatin perturbs ER function, which might also explain other effects of cisplatin on signaling pathways, $\mathrm{Ca}^{2+}$ pump function, and membrane properties. We previously showed that while cisplatin does not induce ER stress, combinatorial use with an ER stress inducer sensitizes resistant worms to cisplatin (Natarajan et al., 2013). This is 
consistent with the idea that cisplatin treatment sensitizes the ER in a metastable state due to TAP targeting defects and if ER function is further compromised then the cells will become hypersensitive to cisplatin cytotoxicity. Further, increased endogenous levels of oxidized ASNA-1 increases cisplatin sensitivity. Drugs that increase ASNA-1 oxidation, target other components of the TAP biogenesis pathway, or induce mild effects on ER function will enhance cisplatin sensitivity, address the problem of cisplatin resistance, and permit lower combinatorial doses. Modeling drug action in non-mammalian genetic model systems is extremely useful for identifying potential protein targets to improve cancer therapy.

\section{Material and Methods}

Plasmids. pVB343ML(Larsen et al., 2007): $1.8 \mathrm{~kb}$ of the intestine-specific vha-6 promoter was cloned as a NheI/SacI fragment into pPD49.26 (Fire lab vector kit). This was used as a backbone for all subsequent cloning with fluorescent markers. pVB637OB and pVB638OB:: GFP or mCherry was amplified without stop codons and inserted as KpnI/NheI fragments after the $v h a-$ 6 promoter in pVB343ML. GFP insertion produced pVB637OB and mCherry produced pVB638OB. pVB641OB: Genomic spcs-1 (SP12) was amplified and inserted as a KpnI/KpnI fragment after and in frame with the mCherry in pVB638OB. pVB643GK: The entire cDNA for $w r b-1$ (Y50D4A.2) was amplified as a HinDIII/HindIII fragment and sub-cloned into the TOPO TA vector. From there it was excised with HindIII and cloned into the L4440 to give pVB643GK. This was the template used to make $w r b-1$ dsRNA with the MegaScript T7 kit (ThermoScientific). pVB644OB: The full-length cDNA of wrb-1 was synthesized as a KpnI/KpnI fragment (GenScript Inc., NJ, USA) and cloned 3' to, and in frame with the GFP in pVB637OB. The entire construct was sequenced and found to be error-free.

GFP::SEC-61 $\beta$ : The open reading frame of Y38F2AR.9 (sec-61 $\beta$ ) was amplified and inserted as a KpnI/KpnI fragment after and in frame with the GFP in pVB637OB to yield pVB639OB. GFP::CYTB-5.1 The open reading frame of $c y t b-5.1$ (Cytochrome B5) was amplified and inserted as a KpnI/KpnI fragment after and in frame with the GFP in pVB637OB to yield pVB640OB. GFP::SERP-1.1: The genomic region of the TAP serp-1.1 lacking the initiator methionine was amplified with Q5 polymerase and inserted downstream and in frame with GFP in pVB637OB to generate the plasmid pDR28. GFP: SEC-61 $\beta$ lacking the transmembrane domain: The genomic clone for worm sec-61 $\beta$ lacking the TMD was synthesized by Genscript (Piscataway, USA), and the clone lacking the initiator methionine was inserted in frame downstream of GFP in pVB637OB using Gibson ligation technology to yield pGK208.

C. elegans genetics and maintenance. The Bristol strain (N2) was used as wild-type control 
and served as parental line for all subsequent strain constructions. N2, zIs356(daf-16::gfp) and svIs69(daf-28::gfp) are described in WormBase (www.wormbase.org). wrb-1(tm5938\& tm5532) were obtained from the the Mitani lab and NBRP, Tokyo (www.shigen.nig.ac.jp/c.elegans/index.jsp). wrb-1(tm5938) was outcrossed six times to N2 and maintained in trans to the $n T 1$ (qIs51) balancer. asna-1(ok938)/hT2(qIs48) was maintained as previously described (Kao et al., 2007). The asna-1 (gk592672) containing strain VC40357 was outcrossed 13 times using unc-32(e189) and oxTi719 [eft-3p::tdTomato::H2B::unc-54'UTR Cbr-unc-119(+)] as balancers and kept in trans to the hT2(qIs48) balancer. svIs135 [Pvha$6:: g f p:: s e c-61 \beta(Y 38 F 2 A R .9)+P v h a-6:: m$ Cherry $:: S P 12]$ was generated by microinjection of pVB639OB together with $\mathrm{pVB} 641 \mathrm{OB}$ at $50 \mathrm{ng} / \mu \mathrm{l}$ each into wild-type $\mathrm{N} 2$, to generate an extrachromosomal array followed by its genomic integration using gamma irradiation. Integration of the $s v I s 135$ transgene was on the $\mathrm{X}$ chromosome. $s v I s 135$ bearing worms were backcrossed six times to $\mathrm{N} 2$ to eliminate background mutations. svIs 135;asna1(ok938)/hT2(qIs48), svIs135;asna-1(A63V)/hT2(qIs48) and svIs135;wrb1 (tm5938)/nTl(qIs51) strains were generated using the 6x outcrossed version of svIs 135 . svIs 143(Pnhx-2::mCherry::lgg-1) was generated by genomic integration (as above) of $v k E x 1093$ (Gosai et al., 2010) and outcrossed three times to N2. The 3x outcrossed version of svIs 143 was used to generate svIs 143; asna-1(ok938)/hT2(qIs48). svEx917 (Pvha-6::gfp::cytb5.1; Pvha-6::mCh::SP12) was generated by injecting $\mathrm{pVB} 640 \mathrm{OB}$ and $\mathrm{pVB} 641 \mathrm{OB}$ at $50 \mathrm{ng} / \mu \mathrm{l}$ each into wild-type N2. Injection RNAi of $w r b-1$ dsRNA (made using pVB643GK as a template). RNAi was performed as previously described (Billing et al., 2012) ASNA$1:: \mathrm{GFP}\left(s v I_{5} 56\right)$ has been previously described (Kao et al., 2007). ASNA-1 ${ }^{\mathrm{A} 63 \mathrm{~V}}:$ :GFP was generated by mutagenesis of pVB222GK (Kao et al., 2007) as a template to introduce the A63V change by the QuickChange II Site-Directed Mutagenesis Kit (Agilent Technologies). The ASNA-1 ${ }^{\mathrm{A} 63 \mathrm{~V}}::$ GFP containing plasmid (pGK200) was used for generating the extrachromosomal arrays $\operatorname{rawEx} 8$ and $\operatorname{rawEx} 9$. $\operatorname{rawEx} 8$ bearing worms were irradiated for chromosomal integration to yield the rawIs 16 transgene. Animals bearing rawIs 16 were outcrossed 4 times to $\mathrm{N} 2$ before analysis. The integrated transgene rawIs 13 that expresses asna$1^{C 285 S ; C 288 S}:: G F P$ was obtained by gamma ray irradiation of worms bearing the $s v E x 756$ extrachromosomal transgene (Hemmingsson et al., 2010). The single copy asna$1: \because g f p($ knuSi184) consisted of a $1.4 \mathrm{~kb}$ upstream promoter sequence driving genomic asna-1 coding region to which the GFP coding region was fused just before the stop codon. $t b b-2$ was used as the 3'UTR for this transgene. This was inserted on chromosome II at the ttTi5605 locus using MosSCI technology in the unc-119(ed3) background (Frøkjær-Jensen et al., 2008) by 
Knudra Transgenics. sod-2(gk257), mev-1(kn-1), hsp-4::GFP (zcIs4), unc-119(ed3);oxTi880, gcs-1::GFP (ldIs3) and gst-4::GFP (dvIs 19) were obtained from Caenorhabditis Genetics Center (CGC) (www.cgc.umn.edu). Strain maintenance and experiments were performed at $20^{\circ} \mathrm{C}$.

The GFP::TAP plasmids were co-injected with pVB641OB (each at $50 \mathrm{ng} / \mathrm{uL}$ ) to generate strains to assay TAP localization to the ER. svIs135 expressed GFP::SEC-61 $\beta$, svEx917 expressed GFP::CYTB-5.1, rawEx14 expressed GFP::SERP-1.1 and rawEx21 expressed GFP::SEC-61 $\beta^{\Delta \mathrm{TMD}}$.

The asna-1(4His164) animals were created by deletion of Histidine in position 164 using Crispr-CAS9 technology by Suny Biotech and was maintained over the balancer hT2(qIs48).

The ASNA-1 ${ }^{\Delta H i s 164:: G F P}$ expressing transgene, svEx591 has been described previously (Hemmingsson et al., 2010).

TAP-targeting analysis. Live animals were sedated in $1 \mathrm{mM}$ Levamisole/M9 and mounted onto $2 \%$ agarose pads. The fluorescence signals of the samples were subsequently analysed at $488 \mathrm{~nm}$ and $555 \mathrm{~nm}$ by the Confocal Laser Scanning Microscope (LSM700, Carl Zeiss) with LD C-Apochromat 40x/1.1 W Corr. objective. Image processing of Z-stacks was performed in the ZEN Lite (Carl Zeiss) program while the correlation quantification was done in the image analysis software Volocity (PerkinElmer). Correlation quantification was done using Automatic Thresholding (Costes et al., 2004) method to set thresholds objectively.

Membrane preparations. Synchronized animals were grown to young adults in standard conditions at $20^{\circ} \mathrm{C}$. Harvested animals were washed two times in M9 buffer and lysed in extraction buffer (50 mMTris, pH7.2, $250 \mathrm{mM}$ sucrose, $2 \mathrm{mM}$ EDTA) with a bullet blender. Carcasses were immediately spun down at $2900 \mathrm{x}$ g at $4{ }^{\circ} \mathrm{C}$. Supernatants were then collected and spun for $60 \mathrm{~min}$ at $100000 \mathrm{x}$ g at $4{ }^{\circ} \mathrm{C}$. The supernatant fraction was concentrated using Vivaspin Concentrators (Sigma). The pellet fraction was resuspended in RIPA buffer. Pellet and supernatant fractions were run on a Tris-glycine gel, blotted onto a polyvinylidene diflouride membrane and probed with the anti-GFP antibody [3H9] (Chromotek) or anti-RME1 (Hadwiger et al., 2010).

Insulin assays. Larval arrest phenotypes were scored in the $\mathrm{F} 1$ generation, grown at $20^{\circ} \mathrm{C}$, from $w r b-1$ dsRNA-injected mothers. Worms harboring integrated daf-16::gfp and daf-28::gfp arrays were grown at $20^{\circ} \mathrm{C}$ and imaged using a Nikon Ni-E microscope, equipped with Hammamatsu Orca flash4.0 camera. daf-16::gfp animals were analysed within 10 minutes to 
avoid artifacts due to stressful conditions. DAF-28::GFP uptake by coelomocytes was scored in adult svIs69; ok938, in svIs69; wrb-1(RNAi) worms and in svIs69;asna-1(A63V).

Western blot analysis. Reducing SDS-PAGE: Nematodes were synchronized in young adult stage and homogenized in a T-PER Tissue Protein Extraction Reagent (Thermo Scientific) with Halt Protease and Phosphatase Inhibitor Cocktail (Thermo Scientific). Homogenization was done using the Next Advance cell disruptor and $0.2 \mathrm{~mm}$ stainless steel beads for 3 minutes at $4^{\circ} \mathrm{C}$. Bradford protein assay was performed to measure protein concentration. Samples were boiled for $10 \mathrm{~min}$ in reducing loading buffer (SDS and $\beta$-mercaptoethanol). Mini-PROTEAN TGX stain free gradient precast gels (BioRad) were used for gel electrophoresis in Tris/Glycine/SDS Buffer (BioRad) and Trans-Blot Tubro Transfer System Transfer pack membranes (BioRad) for transfer to PVDF membranes. Non-reducing SDS-PAGE: Protein samples isolated form the nematodes were boiled for $10 \mathrm{~min}$ in non-reducing (without $\beta$ mercaptoethanol) loading buffer prior SDS-PAGE analysis. SDS-PAGE analysis was performed as described above. Antibodies: anti-ASNA-1 antibody, 1:1000 and anti-GFP antibody [3H9] Chromotek, 1:1000. To confirm equal loading, membranes were stripped using Restore Plus (Thermo Scientific) and incubated with anti-alpha tubulin [T5168] (Sigma). Chemiluminescent signals were generated using the Supersignal West Femto detection reagent (Thermo Scientific) and detected using the LAS1000 machine equipped with a cooled CCD camera (Fuji). Each panel in western blot figures is composed of lanes from the same individual gel in which extra lanes between samples were removed.

Pro-oxidant, anti-oxidant treatment and cisplatin treatment. $\mathrm{H}_{2} \mathrm{O}_{2} / \mathrm{CuSO}_{4}$ : Adult worms were washed from the plate 3 times with M9 and incubated in dark with pro-oxidant: $10 \mathrm{mM}$ $\mathrm{H}_{2} \mathrm{O}_{2}$ and $1 \mathrm{mM} \mathrm{CuSO}_{4}$ simultaneously for $30 \mathrm{~min}$. Worms were washed 3 times with $\mathrm{M} 9$ followed by protein isolations. Sodium arsenite (Sigma): Adult worms were washed 3 times with M9 and transferred into the solution containing $5 \mathrm{mM}$ sodium arsenite and incubated for 1h. Worms were washed 3 times with M9 followed by protein isolation. MitoTempo (Sigma): Adult worms were staged by gravity and L1 larvae were collected. Larvae were grown on plates with OP50 for $24 \mathrm{~h}$ and transferred into plates containing $50 \mu \mathrm{M}$ mitoTempo Worms grow on plates with mitoTempo seeded with OP50 bacteria for $48 \mathrm{~h}$. Worms were washed 3 times with M9 followed by protein isolation. Epigallocatechin gallate (EGCG): EGCG (Sigma) containing plates were prepared by spreading $400 \mu \mathrm{M}$ EGCG on the unseeded NGM plate to obtain a final concentration of $28.6 \mu \mathrm{M}$. Spots of concentrated OP50 was used as a source of food after the plates had dried. Mixed stage worms washed and synchronized. The supernatant containing L1 larvae was collected. Larvae were grown on plates with OP50 for $24 \mathrm{~h}$ and L4 
larvae from these plates were transferred onto EGCG plates. Worms grown on plates with EGCG and OP50 for 24h and were transferred onto a fresh EGCG plate for another $24 \mathrm{~h}$. Worms were washed 3 times with M9 followed by protein isolation. Cisplatin treatment: Cisplatin plates were prepared using MYOB media with $2 \%$ agar in which the drug was added at a concentration of $300 \mu \mathrm{g} / \mathrm{mL}$. Cisplatin solution (Accord Healthcare AB) was added to autoclaved medium after cooling down to $52^{\circ} \mathrm{C}$. Adult worms were washed from the plate 3 times with M9 and incubated on cisplatin for 3h. Worms were washed from the cisplatin plates for the protein insolation.

Transmission electron microscopy (TEM). Worms were washed 3x in M9. The anterior portion of the head was cut off in fixative solution, $2.5 \%(\mathrm{v} / \mathrm{v})$ glutaraldehyde in $0.1 \mathrm{M}$ cacodylate. Samples were then incubated overnight in fixative at $4{ }^{\circ} \mathrm{C}$. After washing three times in fixative solution, samples were treated with $1 \%(\mathrm{v} / \mathrm{v})$ osmium tetroxide for $1 \mathrm{~h}$ and then washed twice in distilled water. Dehydration with 50, 70, 95, and $100 \%$ ethanol was followed by infiltration and embedment in Spurr's resin. Using a DiATOME diamond knife on a Leica EM UC7, sections $(60-90 \mathrm{~nm})$ were mounted on copper grids. The grids were then treated with $5 \%$ uranyl acetate in water for 20 minutes, followed by Sato's lead staining for 5 minutes. Sections were examined with a Jeol 1230 transmission electron microscope and images were captured using a Gatan MSC 600CW camera.

Cisplatin sensitivity assay. Cisplatin plates were prepared using MYOB media with $2 \%$ agar in which the drug was added at a concentration of $300 \mu \mathrm{g} / \mathrm{mL}$ or $500 \mu \mathrm{g} / \mathrm{mL}$. Cisplatin solution from a stock at $1 \mathrm{mg} / \mathrm{mL}$ (Accord Healthcare $\mathrm{AB}$ ) was added to autoclaved medium after cooling it to $52^{\circ} \mathrm{C}$. L4 larvae were picked to a new plate and allowed to grow for $24 \mathrm{~h}$ before exposure to cisplatin. Cisplatin exposure was for $24 \pm 1 \mathrm{~h}$ at $20^{\circ} \mathrm{C}$ and death was determined by absence of touch- provoked movement when worms were stimulated by a platinum wire.

RNA isolation and quantitative PCR. Synchronized young adult worms were washed with M9 solution and transferred into RNase free tubes. Total RNA was extracted from worms suspended in around $25 \mu \mathrm{L}$ of M9 and $360 \mu \mathrm{L}$ of NucleoZOL (Macherry-Nagle) and disrupted by six freeze-thaw cycles between a dry ice/ethanol bath and a $37^{\circ} \mathrm{C}$ water bath. Aurum Total RNA Mini Kit (BioRad) was used; cDNA was synthesized using iScript cDNA Synthesis Kit (BioRad). qPCR was performed on a StepOnePlus Real-Time PCR System (Applied Biosystems) instrument using KAPA SYBR FAST qPCR Kit (KapaBiosystems) with the comparative $\mathrm{Ct}$ method and normalization to the housekeeping gene F44B9.5. All samples were tested in triplicate.

Statistical analysis. Statistical analysis was performed with Prism 7 software (GraphPad 
software, La Jolla, CA, USA). Statistical significance was determined using a Student's t-test or One-way ANOVA. P-values $<0.05$ indicated statistical significance.

Immunoprecipitation assay. Nematodes were grown on NGM plates with OP50 for 4 days. Worms were washed 3 times with M9, lysed using Next Advance cell disruptor with $0.2 \mathrm{~mm}$ stainless steel beads for 3 minutes at $4{ }^{\circ} \mathrm{C}$ in lysis buffer $(10 \mathrm{mM}$ Tris $/ \mathrm{Cl}, 150 \mathrm{mM} \mathrm{NaCl}, 0.5 \mathrm{mM}$ EDTA, 0,5\% NP-40). Bradford protein assay was performed to measure protein concentration. Lysate was added to $35 \mu \mathrm{l}$ of GFP-Trap ${ }^{\circledR} \_$MA magnetic beads (Chromotek) and tumbled endover-end for 1 hour at $4^{\circ} \mathrm{C}$. Beads were magnetically separated and washed 3 times with $500 \mu 1$ of wash buffer I $(0,01 \%$ Tween-20 in 50mM TEAB) for $10 \mathrm{~min}$, followed by 3 times wash II (50mM TEAB) for $10 \mathrm{~min}$. Elution of protein from the beads was performed by adding $50 \mu 1$ $0.2 \mathrm{M}$ glycine ( $\mathrm{pH} 2.5$ ) for $30 \mathrm{sec}$, followed by magnetic separation. $5 \mu 11 \mathrm{M}$ Tris base (pH10.4) was added for neutralization. GFP expressing strain (unc-119(ed3);oxTi880) was used as a negative control for GFP-interacting partners. Experiment was performed three times for identification of WRB-1 as an interacting partner.

Carbonylated protein detection. Protein carbonylation was determined by OxyBlot Protein Oxidation Detection Kit (Millipore). Wild-type animals were synchronized to the young adult stage. Worms were exposed to cisplatin at concentration of $300 \mu \mathrm{g} / \mathrm{mL}$ for 3 or 6 hours. Next worms were washed off the plate using M9 solution. Worms were homogenized as described above. Protein estimation was done using Bradford assay (Bio-Rad). Total extracted proteins $(20 \mu \mathrm{g})$ were derivatized according to the manufacturer's instructions (Millipore). 2mercaptoethanol was used to reduce samples. The membrane was blocked for 1 hour in $1 \%$ BSA/TBS-T and probed with antibodies provided in the kit according to the manufacturer's instructions (Millipore).

Estimation of oxidative stress. Reactive oxygen species (ROS) formation was quantified using 2,7- dichlorodihydrofluorescein diacetate $\left(\mathrm{H}_{2}\right.$ DCFDA) in the control vs. cisplatin treated worms. For cisplatin treated animals: Approximately 1000 worms were transferred to the cisplatin plate and incubated for $3 \mathrm{~h}$ (with concentrated OP50 as a source of food). After the incubation worms were washed off and cleaned from the bacteria and left in about $100 \mu \mathrm{L}$ M9, then transferred to assay well of 96 well plate. $100 \mu \mathrm{L}$ of $100 \mu \mathrm{M}$ of 2,7dichlorodihydrofluorescein diacetate $\left(\mathrm{H}_{2} \mathrm{DCFDA}\right)$ (Thermo Fisher Scientific) was added to achieve a final concentration of $50 \mu \mathrm{M} \mathrm{H}_{2}$ DCFDA. For control animals: Approximately 1000 worms in about $100 \mu \mathrm{L}$ M9 were transferred to assay well of 96 well plate and addition of 100 $\mu \mathrm{L}$ of $100 \mu \mathrm{M}$ 2,7- dichlorodihydrofluorescein diacetate ( $\mathrm{H}_{2} \mathrm{DCFDA}$ ) (Thermo Fisher Scientific), so as to achieve a final concentration of $50 \mu \mathrm{M} \mathrm{H}_{2}$ DCFDA. Fluorescence was read 
at the time of adding the dye and one hour after addition of dye, using fluorimeter $\{485$ excitations, 520 emissions\}. Initial readings were subtracted from the final readings and fluorescence per 1000 worms was calculated.

\section{ACKNOWLEDGEMENTS}

We thank the Caenorhabditis Genetic Center (funded by NIH Office of Research Infrastructure Programs P40 OD010440) and National Bioresource Project for the Experimental Animal "Nematode C. elegans" for providing strains, the Centre for Cellular Imaging at the University of Gothenburg and the National Microscopy Infrastructure, NMI (VR-RFI 2016-00968) for providing assistance in microscopy, Proteomics Core Facility of Sahlgrenska Academy, University of Gothenburg for proteomic analysis, members of Simon Tuck and Marc Pilon labs for scientific discussions and G. Wolfstetter, K. Pfeifer, J. Nilsson and L. Nilsson for helpful comments on the manuscript.

\section{Author contributions}

D.R., O.B., A.P., G.K., O.H. and P.N. designed experiments. D.R., O.B., A.P. and G.K. performed the experiments. D.R., O.B., A.P. and G.K. analyzed the data. D.R., O.B., A.P., G.K., O.H. and P.N. wrote the paper. All authors discussed the results and conclusions in the manuscript

\section{COMPETING INTERESTS}

The authors declare no competing interests.

\section{FUNDING}

The work was supported by grants from the Swedish Cancer Society CAN 2015/599 (P.N.) and ALF means nr: ALFGBG-722971 (P.N.);

\section{DATA AND MATERIALS AVAILABILITY}

All data is available in the main text or the supplementary materials.

\section{REFERENCES}

Abell, B. M., Rabu, C., Leznicki, P., Young, J. C. and High, S. (2007). Post-translational integration of tail-anchored proteins is facilitated by defined molecular chaperones. $J$. Cell Sci. 120, 1743-1751.

Aviram, N. and Schuldiner, M. (2017). Targeting and translocation of proteins to the 
endoplasmic reticulum at a glance. J. Cell Sci. 130, 4079-4085.

Aviram, N., Ast, T., Costa, E. A., Arakel, E. C., Chuartzman, S. G., Jan, C. H., Haßdenteufel, S., Dudek, J., Jung, M., Schorr, S., et al. (2016). The SND proteins constitute an alternative targeting route to the endoplasmic reticulum. Nature 540, 134138.

Back, P., De Vos, W. H., Depuydt, G. G., Matthijssens, F., Vanfleteren, J. R. and Braeckman, B. P. (2012). Exploring real-time in vivo redox biology of developing and aging Caenorhabditis elegans. Free Radic. Biol. Med. 52, 850-859.

Billing, O., Natarajan, B., Mohammed, A., Naredi, P. and Kao, G. (2012). A directed RNAi screen based on larval growth arrest reveals new modifiers of C. elegans insulin signaling. PLoS One 7, e34507.

Brozovic, A., Ambriović-Ristov, A. and Osmak, M. (2010). The relationship between cisplatin-Induced reactive oxygen species, glutathione, and BCL-2 and resistance to cisplatin. Crit. Rev. Toxicol. 40, 347-359.

Carvalho, H. J. F., Bondio, A. Del, Maltecca, F., Colombo, S. F. and Nica Borgese, \& (2019). The WRB Subunit of the Get3 Receptor is Required for the correct integration of its partner cAML into the eR. Sci. Rep. 9, 11887.

Casson, J., McKenna, M., Haßdenteufel, S., Aviram, N., Zimmerman, R. and High, S. (2017). Multiple pathways facilitate the biogenesis of mammalian tail-anchored proteins. J. Cell Sci. 130, 3851-3861.

Chio, U. S., Chung, S., Weiss, S. and Shan, S. (2019). A Chaperone Lid Ensures Efficient and Privileged Client Transfer during Tail-Anchored Protein Targeting. Cell Rep. 26, 3744.e7.

Cho, H. and Shan, S.-O. (2018). Substrate relay in an Hsp70-cochaperone cascade safeguards tail-anchored membrane protein targeting. EMBO J. 37, e99264.

Choi, Y.-M., Kim, H.-K., Shim, W., Anwar, M. A., Kwon, J.-W., Kwon, H.-K., Kim, H. J., Jeong, H., Kim, H. M., Hwang, D., et al. (2015). Mechanism of Cisplatin-Induced Cytotoxicity Is Correlated to Impaired Metabolism Due to Mitochondrial ROS Generation. PLoS One 10, e0135083.

Colombo, S. F., Longhi, R. and Borgese, N. (2009). The role of cytosolic proteins in the insertion of tailanchored proteins into phospholipid bilayers. J. Cell Sci. 122, 2383- 
2392.

Colombo, S. F., Cardani, S., Maroli, A., Vitiello, A., Soffientini, P., Crespi, A., Bram, R. F., Benfante, R. and Borgese, N. (2016). Tail-anchored protein insertion in mammals function and reciprocal interactions of the two subunits of the TRC40 receptor. J. Biol. Chem. 291, 15292-15306.

Costes, S. V., Daelemans, D., Cho, E. H., Dobbin, Z., Pavlakis, G. and Lockett, S. (2004). Automatic and quantitative measurement of protein-protein colocalization in live cells. Biophys. J. 86, 3993-4003.

Dasari, S. and Tchounwou, P. B. (2014). Cisplatin in cancer therapy: Molecular mechanisms of action. Eur. J. Pharmacol. 740, 364-378.

David, D. C., Ollikainen, N., Trinidad, J. C., Cary, M. P., Burlingame, A. L. and Kenyon, C. (2010). Widespread protein aggregation as an inherent part of aging in C. elegans. PLoS Biol. 8, 47-48.

Farkas, A., De Laurentiis Ines, E. and Schwappach, B. (2019). The natural history of Get3-like chaperones. Traffic 20, 311-324.

Favaloro, V., Spasic, M., Schwappach, B. and Dobberstein, B. (2008). Distinct targeting pathways for the membrane insertion of tail-anchored (TA) proteins. J. Cell Sci. 121, $1832-1840$.

Frøkjær-Jensen, C., Wayne Davis, M., Hopkins, C. E., Newman, B. J., Thummel, J. M., Olesen, S. P., Grunnet, M. and Jorgensen, E. M. (2008). Single-copy insertion of transgenes in Caenorhabditis elegans. Nat. Genet. 40, 1375-1383.

Gems, D., Sutton, A. J., Sundermeyer, M. L., Albert, P. S., King, K. V, Edgley, M. L., Larsen, P. L. and Riddle, D. L. (1998). Two Pleiotropic Classes of daf-2 Mutation Affect Larval Arrest, Adult Behavior, Reproduction and Longevity in Caenorhabditis elegans. Genetics 150, 129-155.

Gosai, S. J., Kwak, J. H., Luke, C. J., Long, O. S., King, D. E., Kovatch, K. J., Johnston, P. A., Shun, T. Y., Lazo, J. S., Perlmutter, D. H., et al. (2010). Automated highcontent live animal drug screening using $\mathrm{C}$. elegans expressing the aggregation prone serpin $\alpha 1$-antitrypsin Z. PLoS One 5, e14460.

Gracheva, E. O., Burdina, A. O., Touroutine, D., Berthelot-Grosjean, M., Parekh, H. and Richmond, J. E. (2007). Tomosyn Negatively Regulates CAPS-Dependent Peptide 
Release at Caenorhabditis elegans Synapses. J. Neurosci. 27, 10176-10184.

Guna, A., Volkmar, N., Christianson, J. C. and Hegde, R. S. (2018). The ER membrane protein complex is a transmembrane domain insertase. Science (80-. ). 359, 470-473.

Hadwiger, G., Dour, S., Arur, S., Fox, P. and Nonet, M. L. (2010). A monoclonal antibody Toolkit for C. elegans. PLoS One 5,

Hegde, R. S. and Keenan, R. J. (2011). Tail-anchored membrane protein insertion into the endoplasmic reticulum. Nat. Rev. Mol. Cell Biol. 12, 787-798.

Hemmingsson, O., Nöjd, M., Kao, G. and Naredi, P. (2009). Increased sensitivity to platinating agents and arsenite in human ovarian cancer by downregulation of ASNA1. Oncol. Rep. 22, 869-875.

Hemmingsson, O., Kao, G., Still, M. and Naredi, P. (2010). ASNA-1 activity modulates sensitivity to cisplatin. Cancer Res. 70, 10321-10328.

Henau, S. De, Tilleman, L., Vangheel, M., Luyckx, E., Trashin, S., Pauwels, M., Germani, F., Vlaeminck, C., Vanfleteren, J. R., Bert, W., et al. (2015). A redox signalling globin is essential for reproduction in Caenorhabditis elegans. Nat. Commun. 6, 8782 .

Henderson, S. T. and Johnson, T. E. (2001). daf-16 integrates developmental and environmental inputs to mediate aging in the nematode Caenorhabditis elegans. Curr. Biol. 11, 1975-1980.

Hourihan, J. M., Moronetti Mazzeo, L. E., Fernández-Cárdenas, L. P. and Blackwell, T. K. (2016). Cysteine Sulfenylation Directs IRE-1 to Activate the SKN-1/Nrf2 Antioxidant Response. Mol. Cell 63, 553-566.

Itoh, T., Terazawa, R., Kojima, K., Nakane, K., Deguchi, T., Ando, M., Tsukamasa, Y., Ito, M. and Nozawa, Y. (2011). Cisplatin induces production of reactive oxygen species via NADPH oxidase activation in human prostate cancer cells. Free Radic. Res. 45, 1033-1039.

Kao, G., Nordenson, C., Still, M., Rönnlund, A., Tuck, S. and Naredi, P. (2007). ASNA-1 Positively Regulates Insulin Secretion in C. elegans and Mammalian Cells. Cell 128, $577-587$.

Kelland, L. (2007). The resurgence of platinum-based cancer chemotherapy. Nat. Rev. 
Cancer 7, 573-584.

Knoefler, D., Thamsen, M., Koniczek, M., Niemuth, N. J., Diederich, A.-K. and Jakob, U. (2012). Quantitative In Vivo Redox Sensors Uncover Oxidative Stress as an Early Event in Life. Mol. Cell 47, 767-776.

Komlodi-Pasztor, E., Sackett, D. L. and Fojo, A. T. (2012). Inhibitors Targeting Mitosis:

Tales of How Great Drugs against a Promising Target Were Brought Down by a Flawed Rationale. Clin. Cancer Res. 18, 51-63.

Kumsta, C., Thamsen, M. and Jakob, U. (2011). Effects of Oxidative Stress on Behavior, Physiology, and the Redox Thiol Proteome of Caenorhabditis elegans. Antioxid. Redox Signal. 14, 1023-1037.

Labuschagne, C. F., Stigter, E. C. A., Hendriks, M. M. W. B., Berger, R., Rokach, J., Korswagen, H. C. and Brenkman, A. B. (2013). Quantification of in vivo oxidative damage in Caenorhabditis elegans during aging by endogenous F3-isoprostane measurement. Aging Cell 12, 214-223.

Larsen, M. K., Tuck, S., Færgeman, N. J. and Knudsen, J. (2007). MAA-1, a Novel AcylCoA-binding Protein Involved in Endosomal Vesicle Transport in Caenorhabditis elegans. Mol. Biol. Cell 17, 4318-4329.

Legin, A. A., Schintlmeister, A., Jakupec, M. A., Galanski, M., Lichtscheidl, I., Wagner, M. and Keppler, B. K. (2014). NanoSIMS combined with fluorescence microscopy as a tool for subcellular imaging of isotopically labeled platinum-based anticancer drugs $\dagger$. Chem. Sci 5, 3135-3145.

Lu, J., Zhang, L., Xie, F., Zhu, L., Li, X., Ouyang, J., He, X., Han, S. and Yi, C. (2016). Mild oxidative stress induced by a low dose of cisplatin contributes to the escape of TRAIL-mediated apoptosis in the ovarian cancer SKOV3 cell line. Oncol. Rep. 35, $3427-3434$.

Mateja, A. and Keenan, R. J. (2018). A structural perspective on tail-anchored protein biogenesis by the GET pathway. Curr. Opin. Struct. Biol. 51, 195-202.

Mateja, A., Szlachcic, A., Downing, M. E., Dobosz, M., Mariappan, M., Hegde, R. S. and Keenan, R. J. (2009). The structural basis of tail-anchored membrane protein recognition by Get3. Nature 461, 361-366.

Mateja, A., Paduch, M., Chang, H.-Y., Szydlowska, A., Kossiakoff, A. A., Hegde, R. S. 
and Keenan, R. J. (2015). Structure of the Get3 targeting factor in complex with its membrane protein cargo. Science (80-. ). 347, 1152-1155.

Natarajan, B., Gaur, R., Hemmingsson, O., Kao, G. and Naredi, P. (2013). Depletion of the ER chaperone ENPL-1 sensitizes C. elegans to the anticancer drug cisplatin . Worm 2, e24059.

Norlin, S., Parekh, V. S., Naredi, P. and Edlund, H. (2016). Asna1/TRC40 controls $\beta$-cell function and endoplasmic reticulum homeostasis by ensuring retrograde transport. Diabetes 65, 110-119.

Oláhová, M., Taylor, S. R., Khazaipoul, S., Wang, J., Morgan, B. A., Matsumoto, K., Blackwell, T. K. and Veal, E. A. (2008). A redox-sensitive peroxiredoxin that is important for longevity has tissue-and stress-specific roles in stress resistance. PNAS 105, 19839-19844.

Pan, H., Chen, J., Shen, K., Wang, X., Wang, P., Fu, G., Meng, H., Wang, Y., Jin, B. and Fu, J. (2015). Mitochondrial Modulation by Epigallocatechin 3-Gallate Ameliorates Cisplatin Induced Renal Injury through Decreasing Oxidative/Nitrative Stress, Inflammation and NF-kB in Mice. PLoS One 10, e0124775.

Powis, K., Schrul, B., Tienson, H., Gostimskaya, I., Breker, M., High, S., Schuldiner, M., Jakob, U. and Schwappach, B. (2013). Get3 is a holdase chaperone and moves to deposition sites for aggregated proteins when membrane targeting is blocked. J. Cell Sci. 126, 473-483.

Rivera-Monroy, J., Musiol, L., Unthan-Fechner, K., Farkas, Á., Clancy, A., CoyVergara, J., Weill, U., Gockel, S., Lin, S. Y., Corey, D. P., et al. (2016). Mice lacking WRB reveal differential biogenesis requirements of tail-anchored proteins in vivo. Sci. Rep. 6, e39464.

Schuldiner, M., Metz, J., Schmid, V., Denic, V., Rakwalska, M., Schmitt, H. D., Schwappach, B. and Weissman, J. S. (2008). The GET Complex Mediates Insertion of Tail-Anchored Proteins into the ER Membrane. Cell 134, 634-645.

Speese, S., Petrie, M., Schuske, K., Ailion, M., Ann, K., Iwasaki, K., Jorgensen, E. M. and Martin, T. F. J. (2007). UNC-31 (CAPS) Is Required for Dense-Core Vesicle But Not Synaptic Vesicle Exocytosis in Caenorhabditis elegans. J. Neurosci. 27, 6150-6162.

Srivastava, R., Zalisko, B. E., Keenan, R. J. and Howell, S. H. (2016). The GET System 
Inserts the Tail-Anchored Protein, SYP72, into Endoplasmic Reticulum Membranes. Plant Physiol. 173, 1137-1145.

Stefanovic, S. and Hegde, R. S. (2007). Identification of a Targeting Factor for Posttranslational Membrane Protein Insertion into the ER. Cell 128, 1147-1159.

Stewart, D. J. (2007). Mechanisms of resistance to cisplatin and carboplatin. Crit. Rev. Oncol. Hematol. 63, 12-31.

Thompson, O., Edgley, M., Strasbourger, P., Flibotte, S., Ewing, B., Adair, R., Au, V., Chaudhry, I., Fernando, L., Hutter, H., et al. (2013). The million mutation project: A new approach to genetics in Caenorhabditis elegans. Genome Res. 23, 1749-1762.

Vilardi, F., Lorenz, H. and Dobberstein, B. (2011). WRB is the receptor for TRC40/Asna1mediated insertion of tail-anchored proteins into the ER membrane. J. Cell Sci. 124, $1301-1307$.

Voth, W., Schick, M., Gates, S., Li, S., Vilardi, F., Gostimskaya, I., Southworth, D. R., Schwappach, B. and Jakob, U. (2014). The protein targeting factor Get3 functions as ATP-Independent chaperone under oxidative stress conditions. Mol. Cell 56, 116-127.

Walther, D. M., Kasturi, P., Zheng, M., Pinkert, S., Vecchi, G., Ciryam, P., Morimoto, R. I., Dobson, C. M., Vendruscolo, M., Mann, M., et al. (2015). Widespread Proteome Remodeling and Aggregation in Aging C. elegans. Cell 161, 919-932,.

Xiong, L.-G., Chen, Y.-J., Tong, J.-W., Gong, Y.-S., Huang, J.-A. and Liu, Z.-H. (2018). Epigallocatechin-3-gallate promotes healthy lifespan through mitohormesis during earlyto-mid adulthood in Caenorhabditis elegans. Redox Biol. 14, 305-315.

Zhang, L., Jie, G., Zhang, J. and Zhao, B. (2009). Significant longevity-extending effects of EGCG on Caenorhabditis elegans under stress. Free Radic. Biol. Med. 46, 414-421. 


\section{FIGURES}
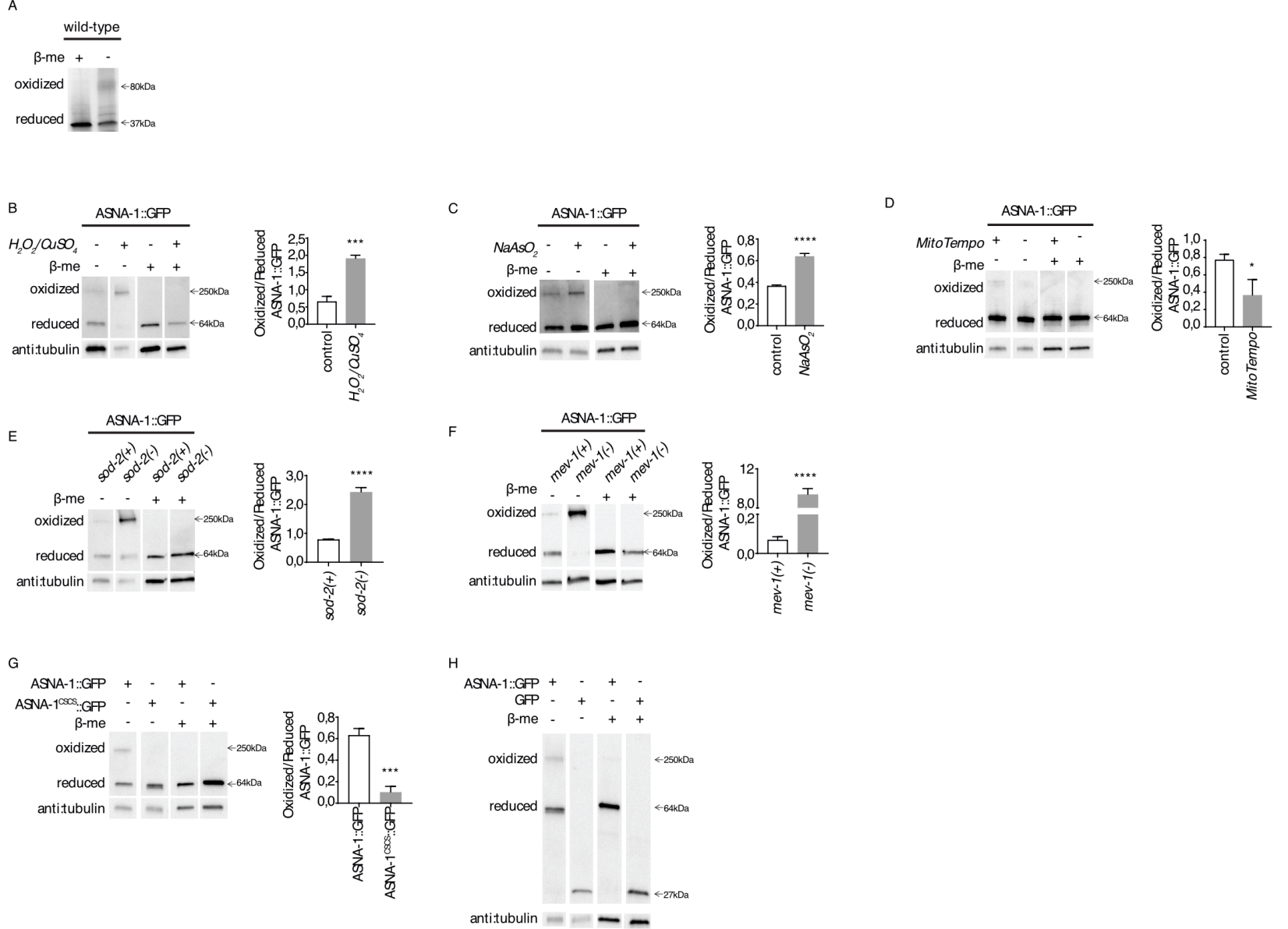

\section{Figure 1. ASNA-1 is present in oxidized and reduced states}

(A) Reducing and non-reducing SDS-PAGE visualizes oxidized and reduced ASNA-1 in the N2 strain. The blot was probed with anti-ASNA-1 antibody.

Reducing and non-reducing SDS-PAGE visualizes oxidized and reduced ASNA-1::GFP:

(B) exposed to $10 \mathrm{mM} \mathrm{H}_{2} \mathrm{O}_{2} / 1 \mathrm{mM} \mathrm{CuSO}_{4}$ for $30 \mathrm{~min}$;

(C) exposed to $5 \mathrm{mM} \mathrm{NaAsO}_{2}$ for $1 \mathrm{~h}$;

(D) exposed to the antioxidant MitoTempo $50 \mu \mathrm{M}$ for $48 \mathrm{~h}$;

(E) in sod-2(gk257) mutants;

(F) in mev-1(knl) mutants;

(G) in ASNA-1 ${ }^{\mathrm{C} 2855 ; \mathrm{C} 288 \mathrm{~S}}:$ :GFP transgenics;

(H) in GFP-expressing strain (unc-119(ed3);oxTi880). 
bioRxiv preprint doi: https://doi.org/10.1101/821728; this version posted October 28, 2019. The copyright holder for this preprint (which was not certified by peer review) is the author/funder, who has granted bioRxiv a license to display the preprint in perpetuity. It is made available under aCC-BY 4.0 International license.

Blots were probed with anti-GFP antibody and tubulin was used as a loading control. Every panel represents a single gel. Statistical significance was determined by the independent two-sample t-test (n $\left.\geq 3 ;{ }^{*} \mathrm{p}<0.05, * * \mathrm{p}<0.01,{ }^{* * *} \mathrm{p}<0.001\right)$. Bars represent mean \pm SD. 
A

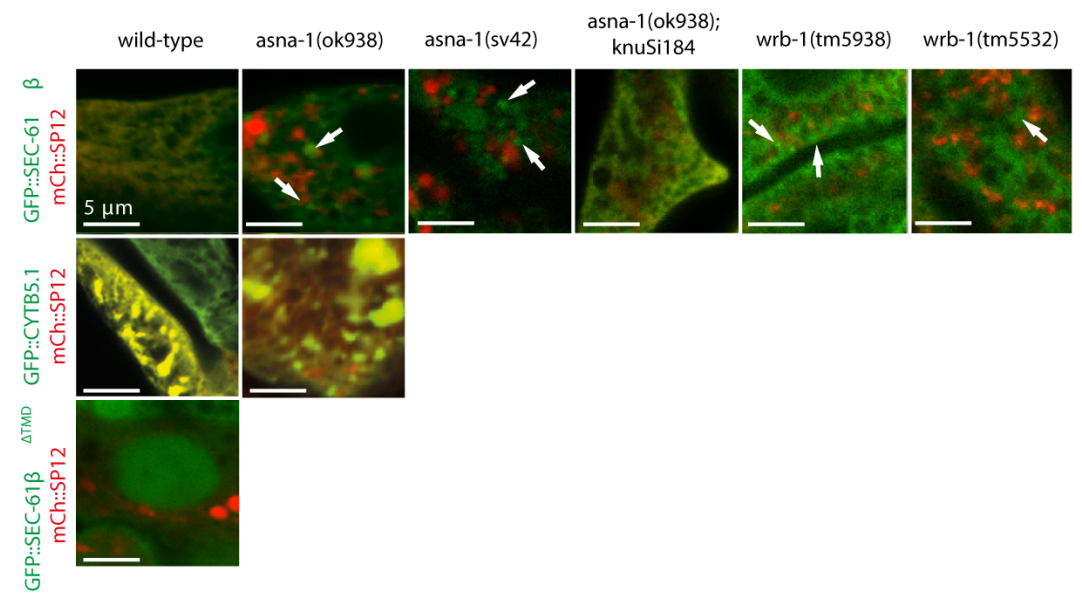

B

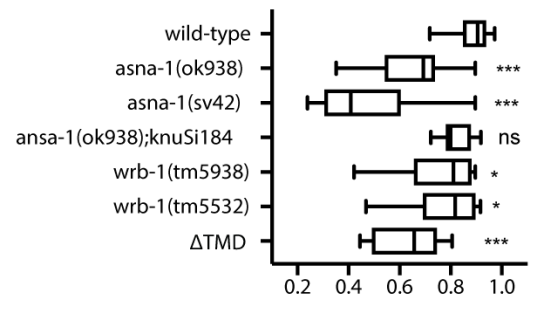

Pearson's correlation coefficient

C
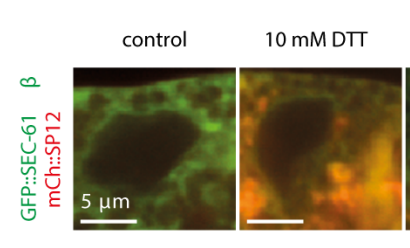

starved

asna-1(ok938); tom-1(ok285)

unc-31(e928)

D

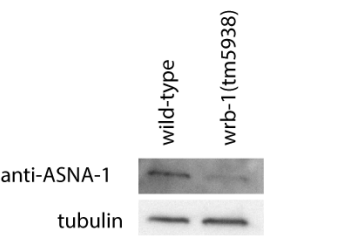

E

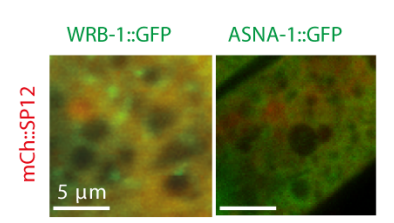

$\mathrm{F}$

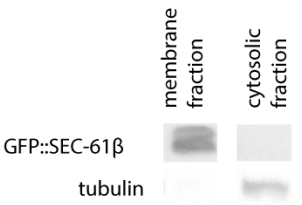

\section{Figure 2. ASNA-1 and WRB-1 promote ER targeting of TAPs in vivo}

(A) Confocal imaging merge of wild-type, asna-1 (ok938), asna-1(sv42), asna-1(ok938);knuSi184, wrb1(tm5938), and wrb-1(tm5532) animals co-expressing GFP::SEC-61 $\beta$ or GFP::CYTB5.1 or GFP::SEC$61 \beta^{\Delta \mathrm{TMT}}$ with mCherry::SP12. White arrows indicate GFP::SEC-61 $\beta$ foci that do not co-localize with mCherry::SP12.

(B) Pearson's correlation analysis of GFP::SEC-61 $\beta$ and mCherry::SP12 co-localization in different strains. Box plot represents the average Pearson correlation coefficient $(\mathrm{R})$ of the indicated strains. Statistical significance was determined by one-way ANOVA followed by Bonferroni post-hoc correction $(\mathrm{n} \geq 10 ; * \mathrm{p}<0.05, * * \mathrm{p}<0.01, * * * \mathrm{p}<0.001)$. 
(C) Confocal imaging merge of animals co-expressing GFP::SEC-61 $\beta$ and mCherry::SP12 with the indicated treatment and genetic backgrounds. White arrows label GFP::SEC-61ß-positive foci that do not co-localize with mCherry::SP12.

(D) Western blot analysis of ASNA-1 levels in wild-type and wrb-1(tm5938) animals. Blot was probed with anti-ASNA-1 antibody and tubulin was used as a loading control.

(E) Confocal imaging merge of animals co-expressing WRB-1::GFP or ASNA-1::GFP and mCherry::SP12.

(F) Subcellular localization of GFP::SEC-61ß. Blot was probed with anti-GFP antibody. Tubulin used as a loading control. 
A
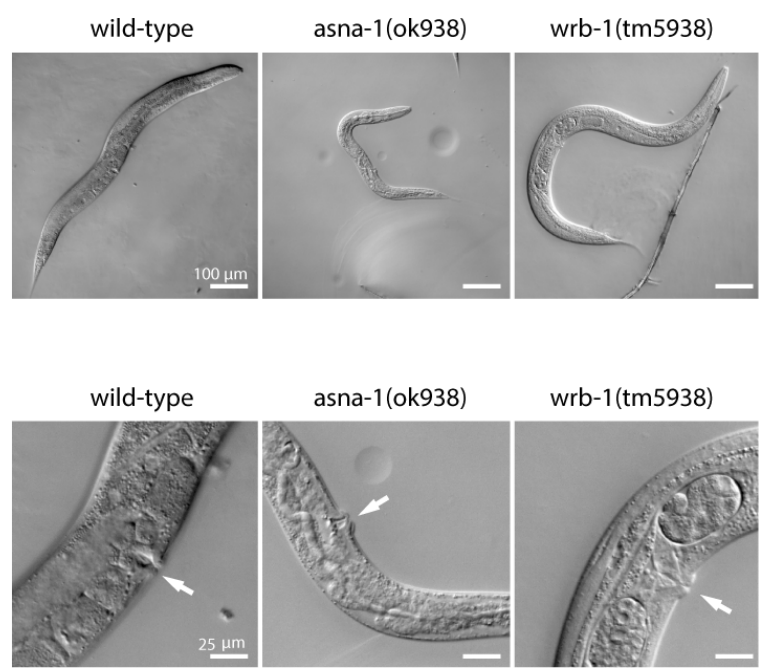

C

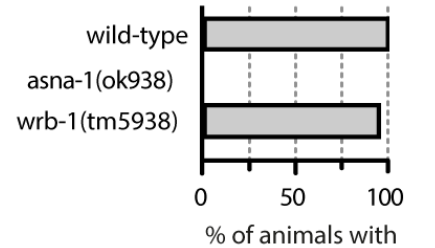

DAF-28::GFP in coelomocytes

D

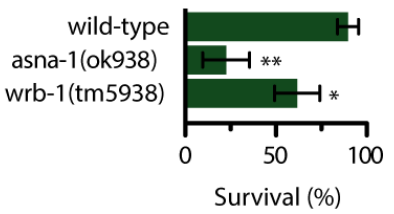

Figure 3. WRB-1 does not have a role in promoting insulin secretion

(A) Representative pictures of whole animals to reveal differences in body size between wild type, asna-1(ok938), and wrb-1(tm5938) strains.

(B) Magnification of the germline from animals shown in (A). White arrows indicate the position of the vulva.

(C) Bar graph plot representing percentage of animals with secreted DAF-28:GFP in coelomocytes $(n \geq 20)$ or the percentage of animals expressing DAF-16::GFP in the cytoplasm $(n \geq 15)$. Error bars represent \pm SD.

(D) Bar graph plot of the mean survival rate of one-day-old young adult animals exposed to cisplatin for $24 \mathrm{~h}$. Statistical significance was determined by the independent two-sample t-test ( $\mathrm{n} \geq 50,{ }^{*} \mathrm{p}$ $<0.05, * * \mathrm{p}<0.01)$. 

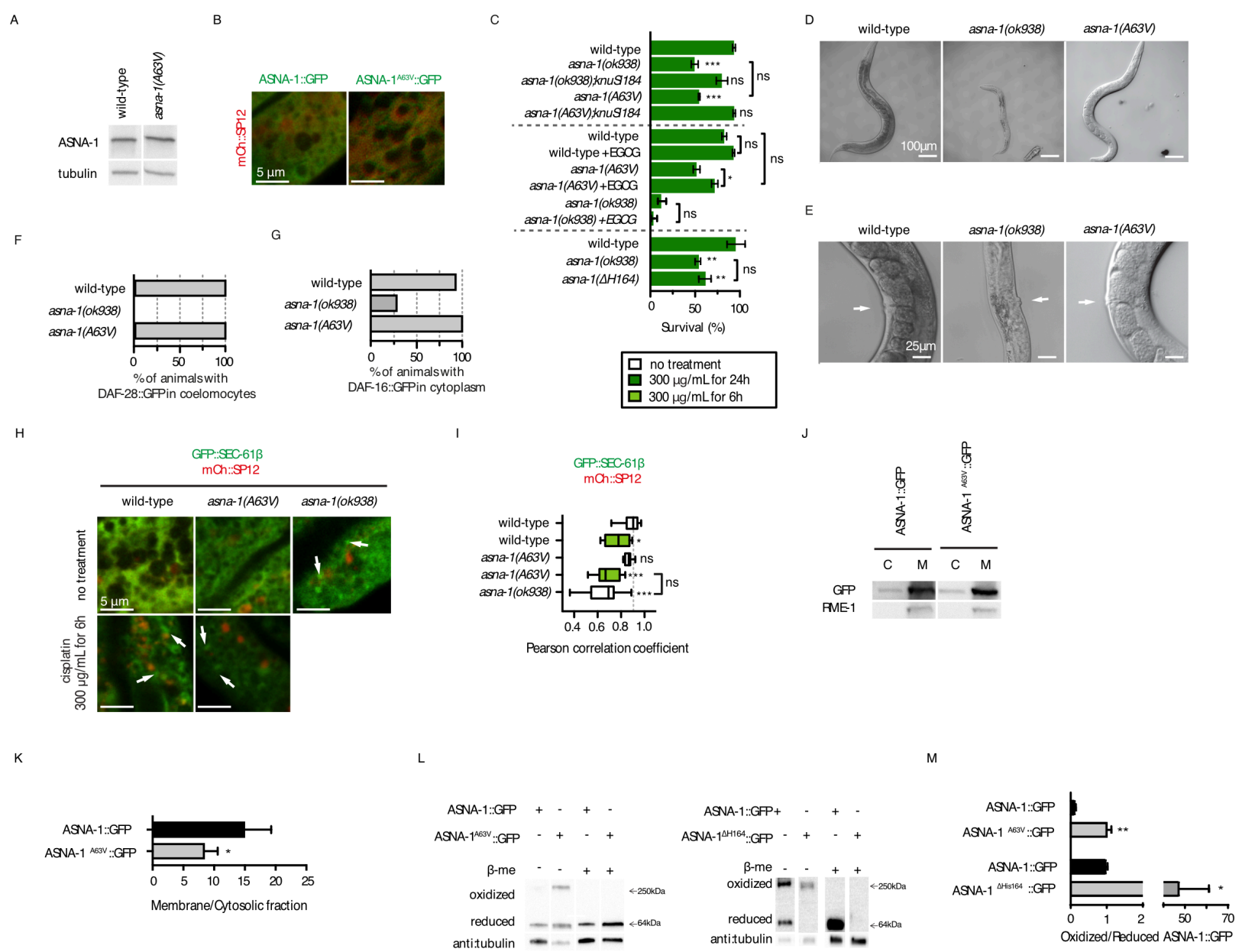

Figure 4. ASNA-1(A63V) increases cisplatin sensitivity via increased levels of oxidized ASNA-1

(A) Western blot analysis of ASNA-1 levels in wild-type and asna-1(A63V) animals. The blot was probed with anti-ASNA-1 antibody and tubulin was used as a loading control.

(B) Confocal imaging merge of animals co-expressing ASNA-1::GFP or ASNA-1 ${ }^{\mathrm{A} 63 \mathrm{~V}}:: \mathrm{GFP}$ with mCherry::SP12.

(C) Bar graph plot representing mean survival $\pm \mathrm{SD}$ of $48 \mathrm{~h}$ young adult animals after $24 \mathrm{~h}$ cisplatin exposure. EGCG pre-treatment: $400 \mu \mathrm{M}$ for $48 \mathrm{~h}$. Statistical significance was determined by independent two-sample t-test ( $\mathrm{n} \geq 50$ ). Error bars represent $\pm S D$.

(D) Representative pictures of animals/adult (hermaphrodites) worms revealing differences in body size between wild type, asna-1(ok938), and asna-1 (A63V) strains.

(E) Magnification of the germline of the animals from (A). White arrows indicate the vulva position.

(F) Bar graph plot representing percentage of animals with secreted DAF-28:GFP in coelomocytes ( $\mathrm{n} \geq$ 20). Error bars represent \pm SD.

(G) Bars graph plot representing percentage of animals expressing DAF-16::GFP in cytoplasm ( $\mathrm{n} \geq 15)$. Error bars represent $\pm \mathrm{SD}$. 
(H) Confocal imaging merge of wild-type, asna-1(A63V), and asna-1(ok938) animals co-expressing GFP::SEC-61 $\beta$ and mCherry::SP12 with or without cisplatin treatment $(300 \mu \mathrm{g} / \mathrm{mL}$ for $6 \mathrm{~h})$.

(I) Pearson correlation analysis of GFP::SEC- $61 \beta$ and mCherry::SP12 colocalization in different strains. Box plot represents the average Pearson correlation coefficient (R) of indicated strains. Statistical significance was determined by one-way ANOVA followed by Bonferroni post-hoc correction $(\mathrm{n} \geq 10$; $* \mathrm{p}<0.05, * * \mathrm{p}<0.01, * * * \mathrm{p}<0.001)$.

(J) Subcellular localization of ASNA-1::GFP and ASNA-1 ${ }^{\mathrm{A} 63 \mathrm{~V}}:$ :GFP. C - cytosolic fraction; M membrane fraction. Blot was probed with anti-GFP antibody. Anti-RME-1 antibody was used as a marker for membrane proteins.

(K) Band intensity quantification of membrane/cytosolic fraction of ASNA-1::GFP and ASNA$1^{\mathrm{A} 63 \mathrm{~V}}:: \mathrm{GFP}$. Statistical significance was determined by the independent two-sample t-test. Error bars represent $\pm \mathrm{SD}$.

(L) Reducing and non-reducing SDS-PAGE visualizes levels of oxidized and reduced ASNA$1^{\mathrm{A} 63 \mathrm{~V}}:: \mathrm{GFP}$ and an ASNA-1 ${ }^{\triangle \mathrm{His} 164}:: \mathrm{GFP}-$ expressing transgenic line. Control refers to worms expressing the wild-type ASNA-1::GFP transgene. Blots were probed with anti-GFP antibody and tubulin was used as a loading control. In each gel the figure is composed of lanes from a single gel.

(M) Band intensity quantification of oxidized/reduced ASNA-1::GFP in different transgenic lines from the experiments in (L). Statistical significance was determined by the independent two-sample t-test. Experiments were performed in triplicate. Error bars represent \pm SD. 
A
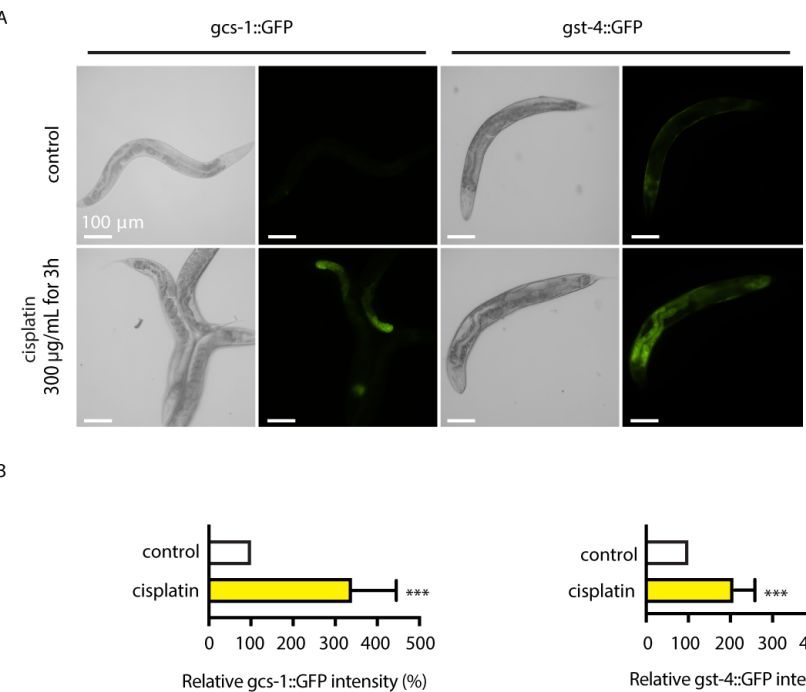

E

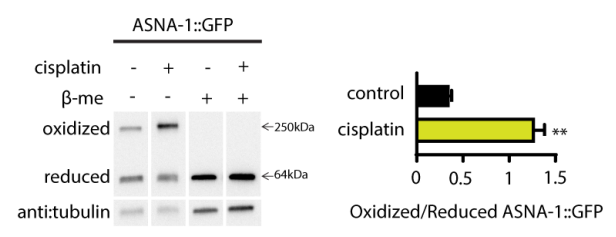

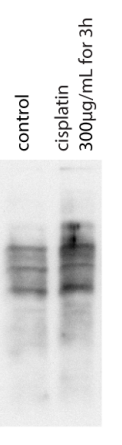

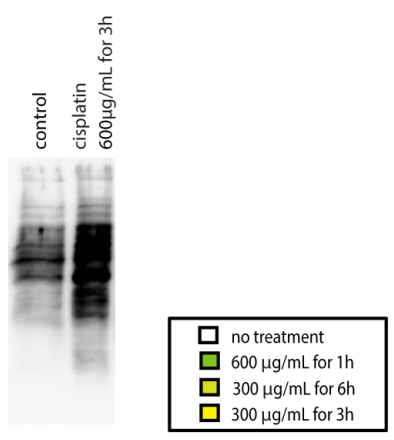

D

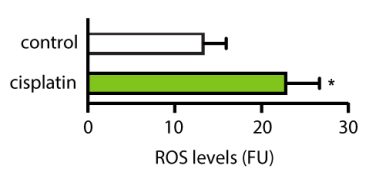

Figure 5. Cisplatin directly increases ROS levels and oxidation of ASNA-1 without affecting insulin secretion.

(A) Increase of GFP intensity upon cisplatin exposure $(300 \mu \mathrm{g} / \mathrm{mL}$ for $3 \mathrm{~h})$ in $g c s-1: \because G F P$ and gst$4: \because G F P$ transgenic strains.

(B) Quantification of relative GFP intensity for $\operatorname{gcs}-1: \because G F P(\mathrm{n} \geq 15)$ and $g s t-4: \because G F P(\mathrm{n} \geq 15)$ transgenic strains. Statistical significance was determined by the independent two-sample t-test ${ }^{*} \mathrm{p}<0.05, * * \mathrm{p}<$ $0.01, * * * \mathrm{p}<0.001)$. Bars represent mean $\pm \mathrm{SD}$.

(C) Influence of cisplatin exposure on protein oxidation evaluated using the OxyBlot kit. Proteins recovered from lysed worms exposed to cisplatin for $3 \mathrm{~h}$ at a concentration of $300 \mu \mathrm{g} / \mathrm{mL}$ or $600 \mu \mathrm{g} / \mathrm{mL}$ were labeled with DNP solution (Oxyblot) to visualize the presence of protein carbonyls by immunoblotting.

(D) ROS production levels as estimated by the $\mathrm{H}_{2}$ DCFDA assay. Wild-type strain was exposed to 600 $\mu \mathrm{g} / \mathrm{mL}$ cisplatin for $1 \mathrm{~h}$. Statistical significance was determined by the independent two-sample t-test ( $\mathrm{n}$ $\geq 1000)$. Experiments were performed in triplicate $(* p<0.05)$. Bars represent mean \pm SD. 
(E) Reducing and non-reducing SDS-PAGE visualizes oxidized and reduced ASNA-1::GFP exposed to cisplatin $(300 \mu \mathrm{g} / \mathrm{ml}$ for $6 \mathrm{~h})$. Blot was probed with anti-GFP antibody and tubulin was used as a loading control. The figure is composed of lanes from a single gel.

(F) Band intensity quantification of oxidized/reduced ASNA-1::GFP exposed to cisplatin $(300 \mu \mathrm{g} / \mathrm{ml}$ for $6 \mathrm{~h}$ ). Statistical significance was determined by the independent two-sample t-test. Error bars represent $\pm \mathrm{SD}$.

(G) Bars represent percentage of animals with secreted DAF-28:GFP in coelomocytes ( $\mathrm{n} \geq 20$ ) exposed to cisplatin $(300 \mu \mathrm{g} / \mathrm{ml}$ for $6 \mathrm{~h})$. Error bars represent $\pm \mathrm{SD}$. 
A

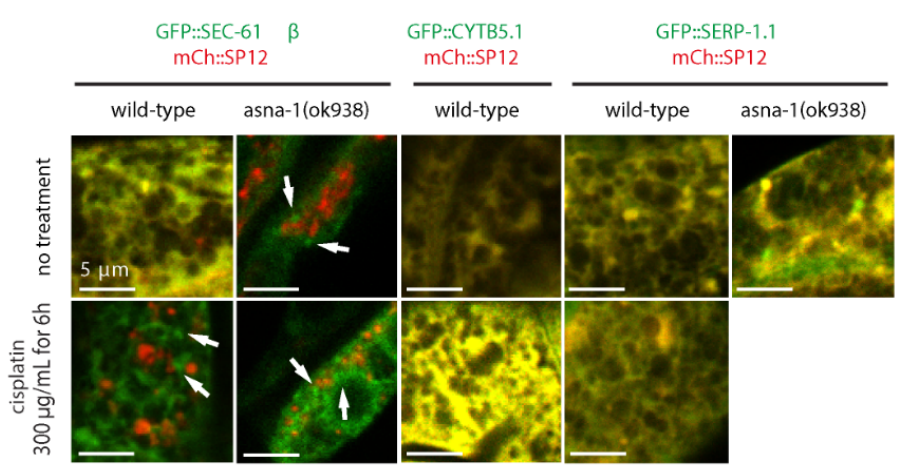

c

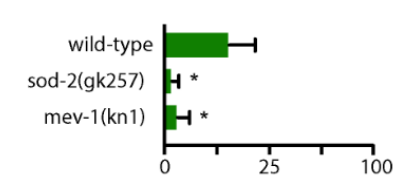

Survival (\%)

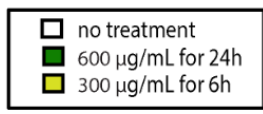

B
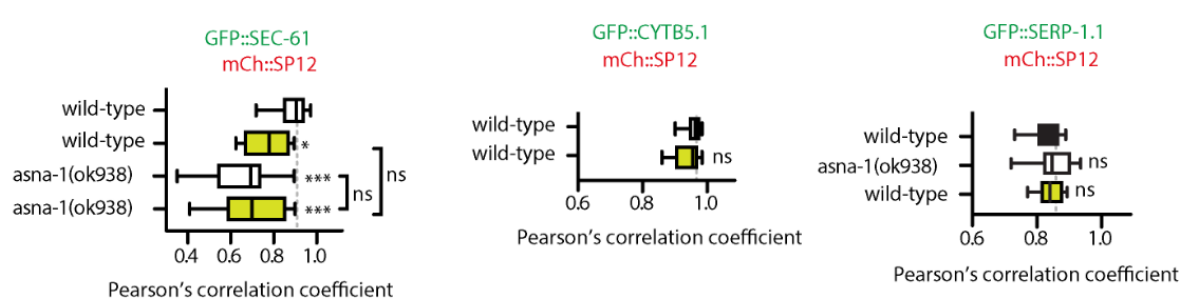

\section{Figure 6. Cisplatin selectively delocalizes ASNA-1-dependent TA protein}

(A) Confocal imaging merge of wild-type or asna-1(ok938) animals co-expressing GFP.:SEC-61 $\beta$, GFP::CYTB5.1, or GFP::SERP-1.1 with mCherry::SP12, with or without cisplatin treatment (300 $\mu \mathrm{g} / \mathrm{mL}$ for $6 \mathrm{~h})$.

(B) Pearson correlation analysis of GFP::SEC-61 $\beta$, GFP::CYTB5.1, or GFP::SERP-1.1 and mCherry::SP12 co-localization. Box plot represent the average Pearson correlation coefficient (R) of the indicated strains without or with cisplatin treatment $(300 \mu \mathrm{g} / \mathrm{mL}$ for $6 \mathrm{~h})$. Statistical significance was determined by one-way ANOVA followed by Bonferroni post-hoc correction $(n \geq 10)$. $\left({ }^{*} p<0.05\right.$, $* * \mathrm{p}<0.01, * * * \mathrm{p}<0.001)$.

(C) Bars represent mean survival $\pm \mathrm{SD}$ of one-day-old young adult animals exposed to cisplatin. Statistical significance was determined by the independent two-sample t-test $(\mathrm{n} \geq 50)$. Experiments were performed in triplicate. 
A

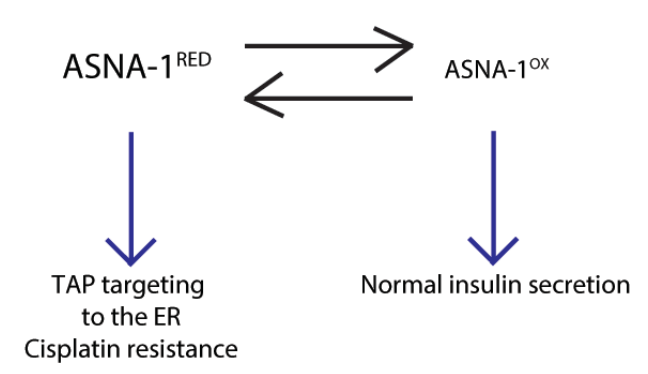

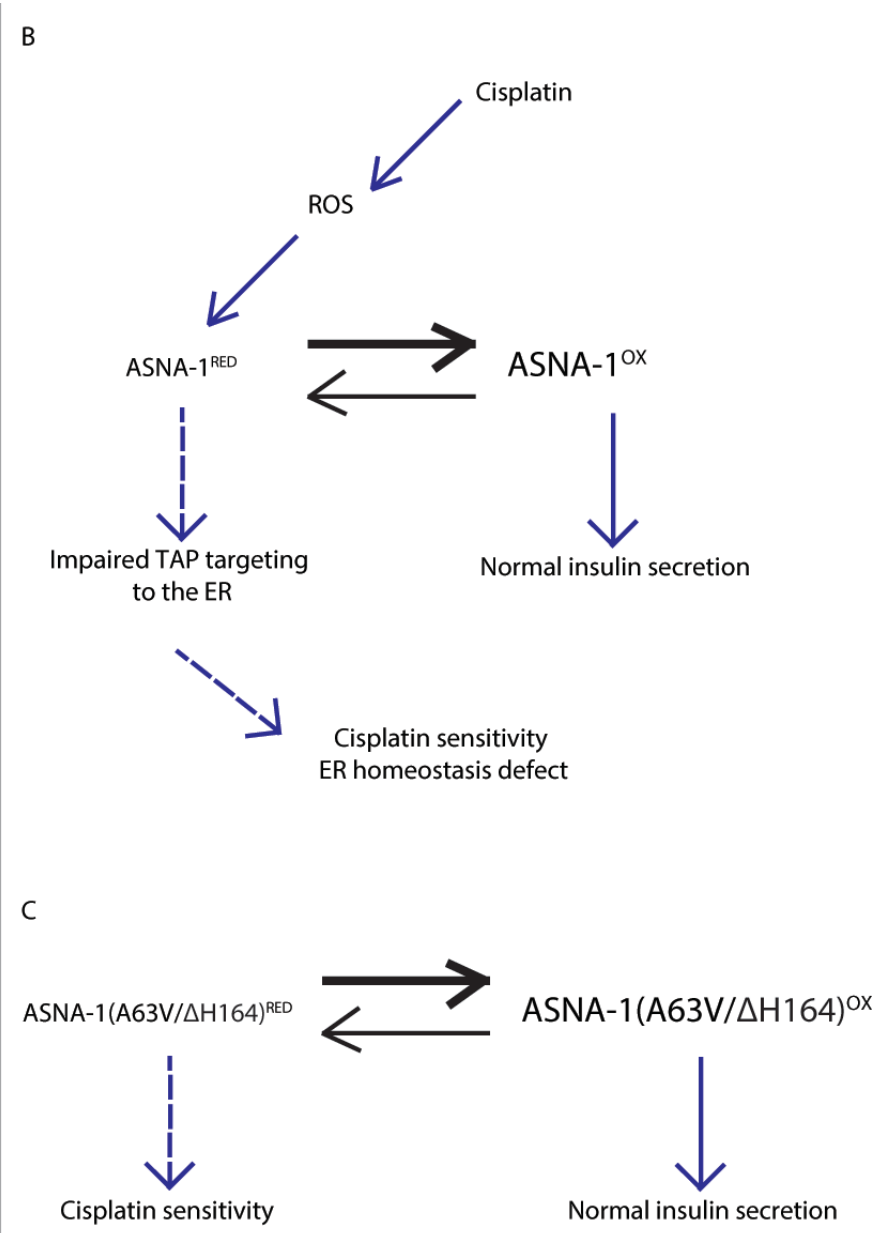

Figure 7. ASNA-1-mediated roles in cellular function and cisplatin sensitivity are based on the balance of its redox states

(A) Under normal physiological conditions, ASNA-1 is present in both forms: reduced (ASNA-1 ${ }^{\text {RED}}$ ) and oxidized (ASNA-1 ${ }^{\mathrm{OX}}$ ). ASNA- ${ }^{\mathrm{RED}}$ participates in the insertion of TAP into the ER membrane, while ASNA-1 ${ }^{\text {OX }}$ assures proper insulin secretion.

(B) When the cells are exposed to cisplatin, elevated ROS levels perturb the ASNA-1 redox balance. ASNA-1 shifts towards the ASNA-1 ${ }^{\text {OX }}$ state at the expense of ASNA-1RED, which impairs TAP targeting to the ER without affecting insulin secretion. Because less ASNA-1 ${ }^{\text {RED }}$ is available, ER homeostasis is affected and cells are more sensitive to cisplatin.

(C) Both ASNA-1-mutant proteins (A63V and $\Delta \mathrm{H} 164$ ) are found predominantly in the ASNA-1 ${ }^{\text {OX }}$ state, which results in greater cisplatin sensitivity but unaffected insulin secretion. 


\section{TABLE}

Table 1. Proteomic identification of ASNA-1 interacting partners. Proteomic analysis of ASNA-1::GFP and GFP control pull down. Table shows: immunoprecipitation number (IP number), accession number of detected protein from UNIPROT (Uniprot ID), protein name detected in the analysis (Protein name), molecular weight of a detected protein (MW (kDa)), percentage of the protein sequence covered by the identified peptides (Coverage (\%)), total number of peptides identified in the protein/protein group (\# Peptides), sequences of the detected peptides, number of peptide spectrum matches for the peptide (\# Peptide Spectrum Matches). 
bioRxiv preprint doi: https://doi.org/10.1101/821728; this version posted October 28, 2019. The copyright holder for this preprint (which was not certified by peer review) is the author/funder, who has granted bioRxiv a license to display the preprint in perpetuity. It is made available under aCC-BY 4.0 International license.

\begin{tabular}{|c|c|c|c|c|c|c|c|c|c|c|}
\hline \multirow[b]{2}{*}{ IP number } & \multirow[b]{2}{*}{$\begin{array}{l}\text { Uniprot } \\
\text { ID }\end{array}$} & \multirow[b]{2}{*}{$\begin{array}{c}\text { Protein } \\
\text { name }\end{array}$} & \multirow[b]{2}{*}{$\begin{array}{l}\mathrm{MW} \\
\text { (kDa) }\end{array}$} & \multicolumn{4}{|c|}{ ASNA-1::GFP } & \multicolumn{3}{|c|}{ GFP Control } \\
\hline & & & & $\begin{array}{c}\text { Coverage } \\
(\%)\end{array}$ & \# Peptides & Sequence of the detected peptides & $\begin{array}{l}\text { \# Peptide } \\
\text { Spectrum } \\
\text { Matches } \\
\end{array}$ & $\begin{array}{c}\text { Coverage } \\
(\%)\end{array}$ & \# Peptides & $\begin{array}{l}\text { \# Peptide } \\
\text { Spectrum } \\
\text { Matches } \\
\end{array}$ \\
\hline 1 & P 30632 & ASNA-1 & 37,5 & 17,84 & 8 & $\begin{array}{c}\text { TPTLVEGFK } \\
\text { LPLLEAEVR } \\
\text { GGPAILQFSER } \\
\text { MVDPEANK } \\
\text { mVDPEANK } \\
\text { LIQELSK } \\
\text { MTTTLESVKK } \\
\text { mTTTLESVK } \\
\text { WIFVGGK } \\
\end{array}$ & 20 & - & - & - \\
\hline 1 & $\mathrm{G} 4 \mathrm{~S} 708$ & WRB-1 & 21,3 & 16,15 & 2 & $\begin{array}{c}\text { ASEELAALEAASPSENSR } \\
\text { ELHGISPTAEFAR }\end{array}$ & 2 & - & - & - \\
\hline 2 & $\mathrm{P} 30632$ & ASNA-1 & 37,5 & 37,43 & 12 & $\begin{array}{c}\text { TPTLVEGFK } \\
\text { LPLLEAEVR } \\
\text { VLLISTDPAHNISDAFSQK } \\
\text { LLQFPTLLEK } \\
\text { MTTTLESVK } \\
\text { mTTTLESVK } \\
\text { MTTTLESVKK } \\
\text { mTTTLESVKK } \\
\text { LIDSLDFDVVVFDTAPTGHTLR } \\
\text { LLeELSK } \\
\text { MVDPEANK } \\
\text { GGPAILQFSER } \\
\text { YLTDIDELYEDFHVVK } \\
\text { WIFVGGK } \\
\end{array}$ & 34 & - & - & - \\
\hline 2 & G4S708 & WRB-1 & 21,3 & 21,35 & 3 & $\begin{array}{c}\text { ASEELAALEAASPSENSR } \\
\text { ELHGISPTAEFAR } \\
\text { SLSKPKPSPK } \\
\end{array}$ & 5 & - & - & - \\
\hline 3 & P 30632 & ASNA-1 & 37,5 & 42,11 & 15 & $\begin{array}{c}\text { VLLISTDPAHNISDAFSQK } \\
\text { mTTTLESVKK } \\
\text { MTTTLESVKK } \\
\text { YLTDIDELYEDFHVVK } \\
\text { TPTLVEGFK } \\
\text { LPLLEAEVR } \\
\text { mTTTLESVK } \\
\text { MTTTLESVK } \\
\text { SDQLEASIK } \\
\text { LIDSLDFDVVVFDTAPTGHTLR } \\
\text { MVDPEANK } \\
\text { LIQELSK } \\
\text { GGPAILQFSER } \\
\text { LLQFPTLLEK } \\
\text { KMNAQFK } \\
\text { mVDPEANK } \\
\text { mVDPEANKN } \\
\text { MVDPEANKN } \\
\text { WIFVGGK } \\
\text { KmNAQFK }\end{array}$ & 273 & - & - & - \\
\hline 3 & G4S708 & WRB-1 & 21,3 & 21,35 & 3 & $\begin{array}{c}\text { ASEELAALEAASPSENSR } \\
\text { ELHGISPTAEFAR } \\
\text { SLSKPKPSPK } \\
\end{array}$ & 5 & - & - & - \\
\hline 3 & Q95XS2 & $\begin{array}{c}\text { Sec61 } \\
\text { Beta }\end{array}$ & 8,6 & 12,35 & 1 & FYTEDSTGLK & 1 & - & - & - \\
\hline
\end{tabular}


bioRxiv preprint doi: https://doi.org/10.1101/821728; this version posted October 28, 2019. The copyright holder for this preprint (which was not certified by peer review) is the author/funder, who has granted bioRxiv a license to display the preprint in perpetuity. It is made available under aCC-BY 4.0 International license.

\section{SUPPLEMENTARY FIGURES}

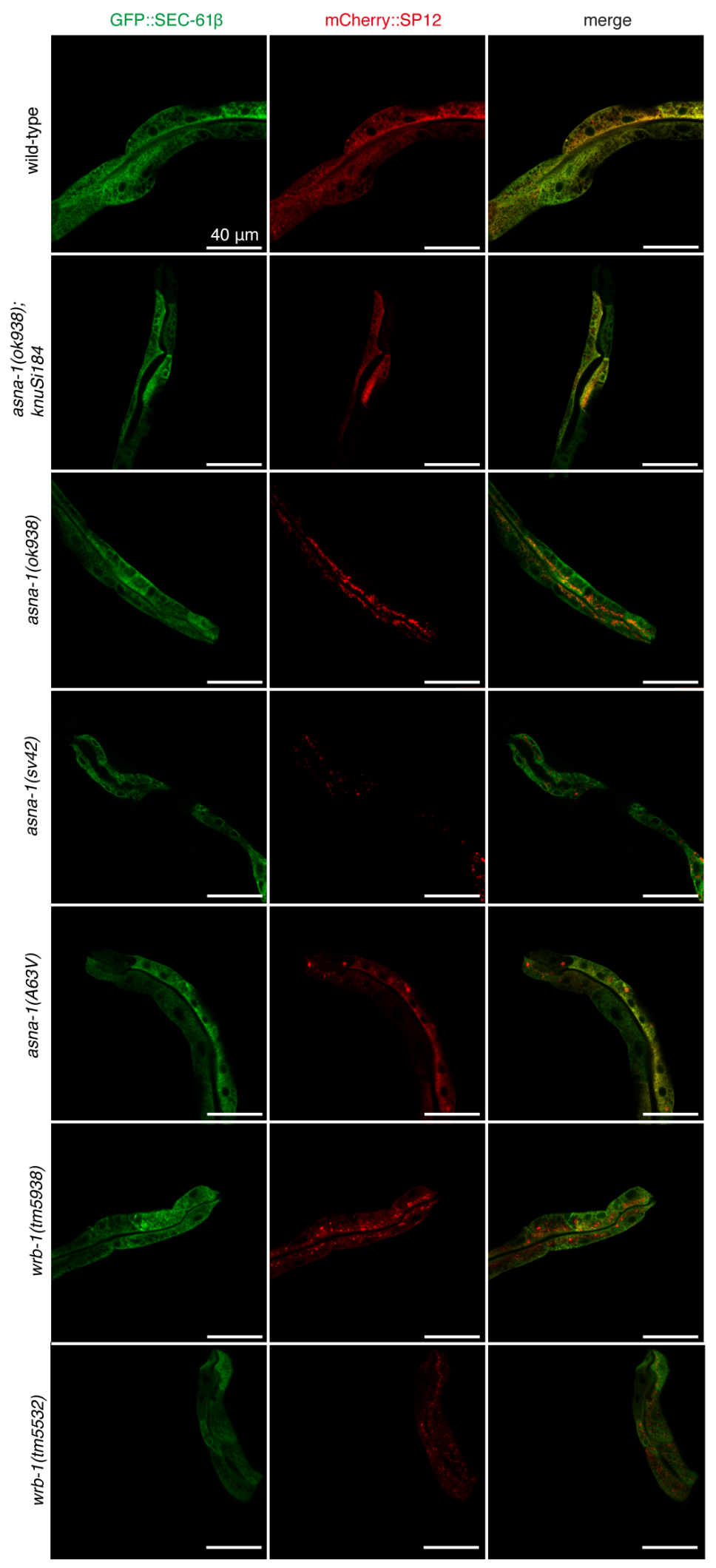

Figure S1. ASNA-1 and WRB-1 promote ER targeting of TAPs in vivo

Confocal imaging of wild-type, asna-1(ok938);knuSi184, asna-1(ok938), asna-1(sv42), asna-1(A63V), 
bioRxiv preprint doi: https://doi.org/10.1101/821728; this version posted October 28, 2019. The copyright holder for this preprint (which was not certified by peer review) is the author/funder, who has granted bioRxiv a license to display the preprint in perpetuity. It is made available under aCC-BY 4.0 International license.

wrb-1(tm5938), or wrb-1(tm5532) and animals co-expressing GFP::SEC-61 $\beta$ and mCherry::SP12. In all cases, posterior intestinal cells were imaged. 
A

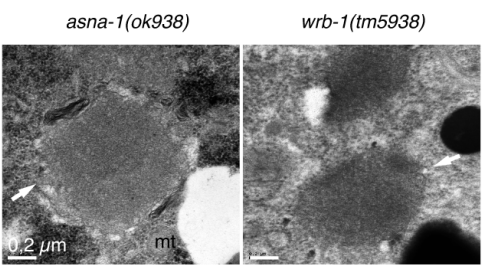

B

wild-type

asna-1(ok938) wrb-1(tm5938)
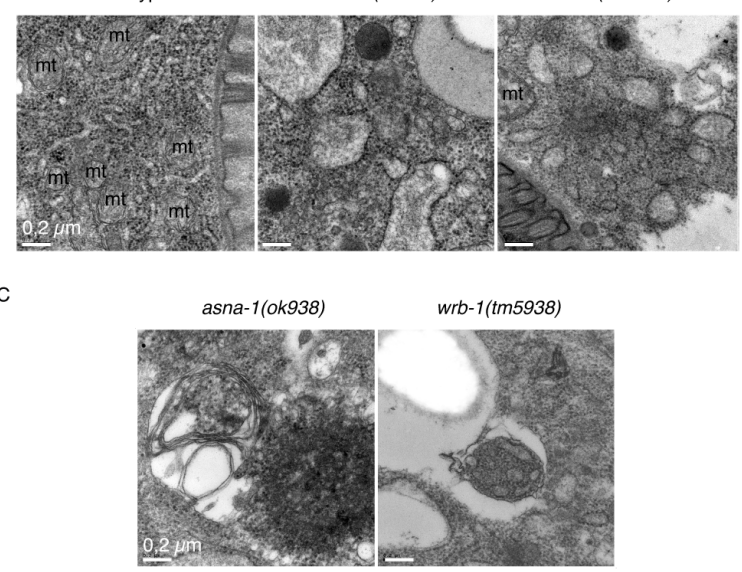

D

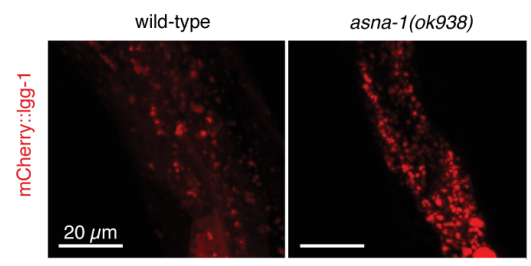

E

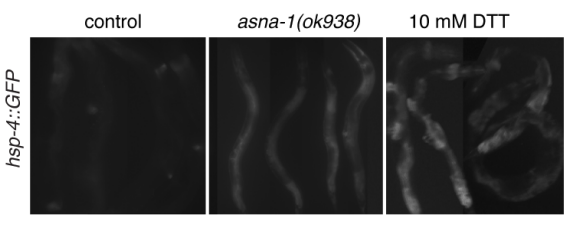

Figure S2. Ultrastructural phenotypes of asna-1(-) and wrb-1(-) animals and autophagy and ER stress levels in asna-1 mutants

(A) Examples of numerous cytosolic inclusion bodies (white arrows) found in the intestinal cells of asna-1(ok938) and wrb-1(tm5938) animals. The black arrowheads highlight examples of membrane whorls that in some cases flank the inclusion bodies in intestinal cells of asna-1(ok938) animals.

(B) Dilated ER lumina in intestinal cells of asna-1(ok938) and wrb-1(tm5938) animals. Black arrowheads indicate rough ER (RER) membranes.

(C) Portions of RER were found to be engulfed in ER-containing autophagosomes (ERAs) in asna1(ok938) and wrb-1(tm5938) animals. 
D) Confocal images of representative adult animals co-expressing mCherry::lgg-1. LGG-1 localization in wild-type animals (left panel) is more diffuse and less punctate compared to asna-1 (ok938) animals (right panel).

(E) Expression from the Phsp-4::GFP reporter imaged by fluorescence microscopy. The reporter induction upon introduction of asna-1(ok938) mutation is comparable to the $10 \mathrm{mM}$ DTT exposure for $4 \mathrm{~h}$. Animals undergoing the L3/L4 molt were excluded from the analysis, since molting caused a sharp increase in Phsp-4::GFP expression. 
A

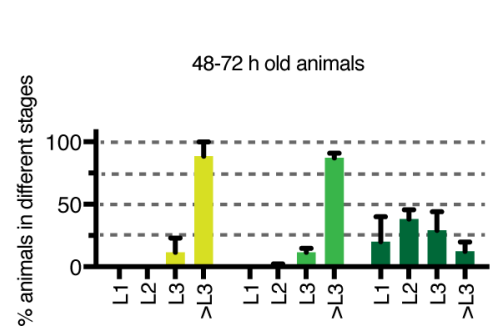

B

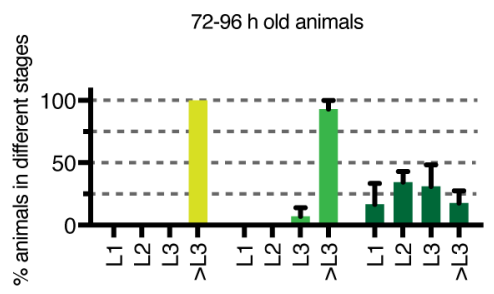

wrb-1(tm5938) wrb-1(RNAi)

wrb-1(tm5938); wrb-1(RNAi)

Figure S3. Depleting both maternal and zygotic wrb-1(m-z) did not reproduce the reversible arrest in the first larval stage characteristic for asna-1(m-z)

wrb-1(tm5938) animals were injected with $w r b-1$ dsRNA into the gonads and allowed to lay eggs for $24 \mathrm{~h}$ before being removed. Animals were scored after $48 \mathrm{~h}(\mathrm{~A})$ and $72 \mathrm{~h}(\mathrm{~B})$ by counting the number of animals in each stage. Bars represent mean \pm SD. 
A

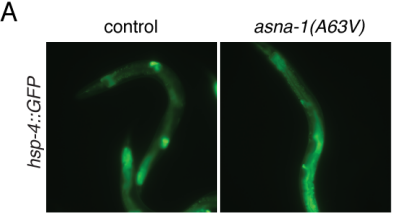

D

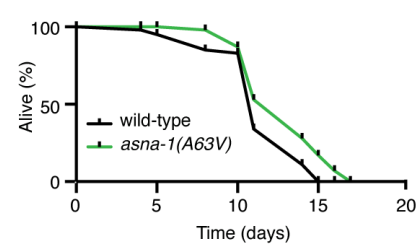

$\mathrm{F}$

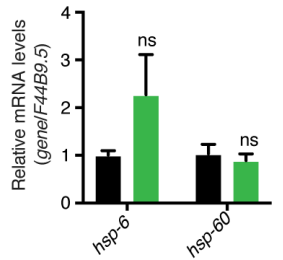

G
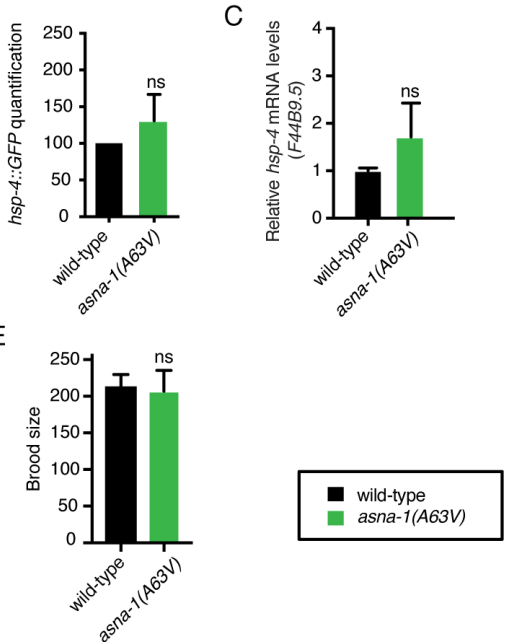

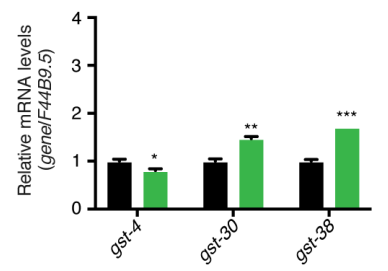

Figure S4. Cellular stress response analysis in asna-1(A63V)

(A) Expression from the Phsp-4::GFP reporter imaged by fluorescence microscopy in the wild-type and asna-1(A63V) animals.

(B) Phsp-4::GFP expression quantification in the wild-type and asna-1(A63V) animals (n $\geq 6)$. Statistical significance was determined by the independent two-sample t-test $\left({ }^{*} \mathrm{p}<0.05,{ }^{*} \mathrm{p}<0.01,{ }^{* * *} \mathrm{p}<0.001\right)$. Bars represent mean $\pm \mathrm{SD}$.

(C) Relative mRNA analysis of ER stress reporter $h s p-4$ in asna-1(A63V) animals. Statistical significance was determined by the independent two-sample t-test $\left({ }^{*} \mathrm{p}<0.05,{ }^{*} \mathrm{p}<0.01,{ }^{* * *} \mathrm{p}<0.001\right)$. Experiments were performed in triplicate $(n=3)$. F44B9.5 was used as a normalizing control. Bars represent mean $\pm \mathrm{SEM}$.

(D) Life span analysis of wild-type and asna-1(A63V) animals ( $\mathrm{n} \geq 42)$.

(E) Brood size analysis of wild-type and asna-1(A63V) $(\mathrm{n}=5)$. Statistical significance was determined by the independent two-sample t-test $\left({ }^{*} \mathrm{p}<0.05,{ }^{* *} \mathrm{p}<0.01,{ }^{* * *} \mathrm{p}<0.001\right)$. Bars represent mean $\pm \mathrm{SD}$.

(F) Relative mRNA analysis of the mitochondrial stress reporters ( $h s p-6$ and $h s p-60$ ) and (G) oxidative stress reporters (gst-4, gst-30 and gst-38) in asna-1(A63V) animals. Statistical significance was determined by the independent two-sample t-test $\left({ }^{*} \mathrm{p}<0.05, * * \mathrm{p}<0.01,{ }^{* * *} \mathrm{p}<0.001\right)$. Experiments were performed in triplicate $(n=3)$. F44B9.5 was used as a normalizing control. Bars represent mean \pm SEM. 